Florida International University FIU Digital Commons

4-23-2004

\title{
Vertical attenuation of light predicts the sequence to dawn song in a tropical forest avifuana
}

Karl Stephen Berg

Florida International University

DOI: $10.25148 /$ etd.FI14051106

Follow this and additional works at: https://digitalcommons.fiu.edu/etd

Part of the Biology Commons

\section{Recommended Citation}

Berg, Karl Stephen, "Vertical attenuation of light predicts the sequence to dawn song in a tropical forest avifuana" (2004). FIU Electronic Theses and Dissertations. 1595.

https://digitalcommons.fiu.edu/etd/1595 
FLORIDA INTERNATIONAL UNIVERSITY

Miami, Florida

\section{VERTICAL ATTENUATION OF LIGHT PREDICTS}

THE SEQUENCE TO DAWN SONG IN A

TOPICAL FOREST AVIFUANA

A thesis submitted in partial fulfillment of the

requirements for the degree of

MASTER OF SCIENCE

in

BIOLOGY

by

Karl Stephen Berg 
To: Dean R. Bruce Dunlap

College of Arts and Sciences

This thesis, written by Karl Stephen Berg, and entitled Vertical Attenuation of Light Predicts the Sequence to Dawn Song in a Tropical Forest Avifauna, having been approved in respect to style and intellectual content, is referred to you for judgment.

We have read this thesis and recommend that it be approved.

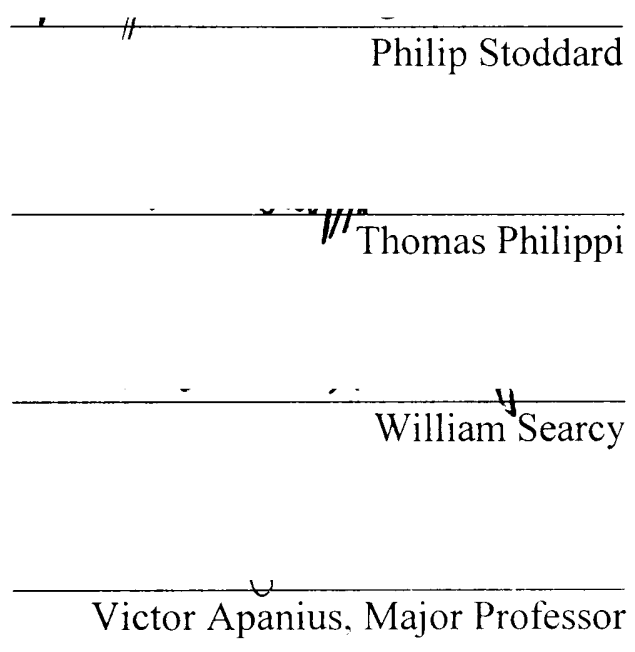

Date of Defense: April 23, 2004

The thesis of Karl Stephen Berg is approved.

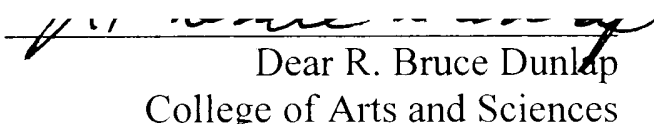

College of Arts and Sciences

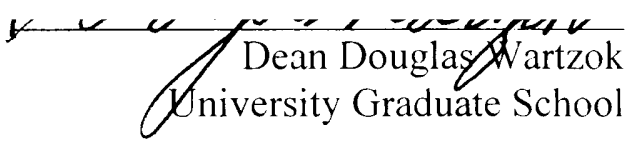

Florida International University, 2004 
(C) Copyright 2004 by Karl Stephen Berg

All rights reserved. 


\section{DEDICATION}

I dedicate this thesis to my parents. Without their patience, understanding, support and most of all love, the completion of this work would not have been possible. 


\section{ACKNOWLEDGMENTS}

This study was supported a fellowship from the Center for Environmental Science, U.S. Environmental Protection Agency (U-91608201), and small grants from World Parks Endowment, Fundación Jocotoco and FIU's Graduate Student Association. The Jatun Sacha Foundation provided access to forests and logistical support. I am especially grateful to my wife, Soraya Delgado, for her love, patience and help with field work. The study would not have been possible without the aid of my advisor Victor Apanius in all aspects of the project. Committee members Philip Stoddard, Thomas Philippi and William Searcy provided much needed critical advice; Robert Ridgely provided financial impetus and inspiration; Michael McColm provided access to forests and logistical help in Ecuador; Philip Stoddard, Vicky Salazar, Timothy Collins, David Lee and Steven Oberbauer loaned equipment and helped with instrumentation; Niels Krabbe, Robert Ridgely and Paul Coopmans helped identify numerous unidentified recordings of birds; Robb Brumfield and Nathan Rice provided eye measurements; the late Tito Santos for hospitality and use of his forest; Greg Budney, Robert Grotke and Olaf Jahn lent technical advice regarding field recording techniques; Van Remsen, Donald Kroodsma, Cynthia Staicer, Robb Brumfield and Timothy Rawlings provided helpful comments on methods; Manuel Tapuyo and Carlos Robles shared their knowledge of forests of western Ecuador; and FIU's peer-review group provide a good sounding board. 


\title{
ABSTRACT OF THE THESIS \\ VERTICAL ATTENUATION OF LIGHT PREDICTS THE SEQUENCE TO \\ DAWN SONG IN A TROPICAL FOREST AVIFAUNA
}

by

\author{
Karl Stephen Berg
}

Florida International University, 2004

Miami, Florida

Professor Victor Apanius, Major Professor

The concentration of avian song at first light (i.e., the dawn chorus) is widely appreciated but has an enigmatic functional significance. The most widely accepted explanation is that birds are active but light levels are not adequate for foraging. As a consequence, the time of first song should be predictable from the light level of individuals singing at dawn. To test this, I collected data from a tropical forest of Ecuador, involving 130 species. Light intensity at first song was a highly repeatable species' trait $(r=0.57)$. Foraging height was a good predictor of first song, with canopy birds singing at lower light levels than understory birds $(r=-0.62)$. Although light level predicts the onset of singing in tropical and temperate bird communities, the structural complexity and trophic specializations in tropical forests may exert an important influence, which has been overlooked in research conducted in the temperate zone. 


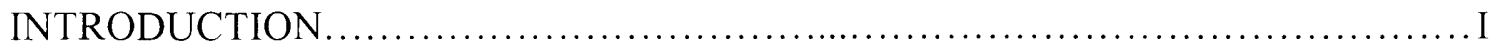

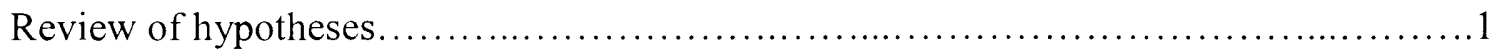

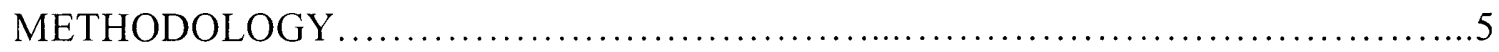

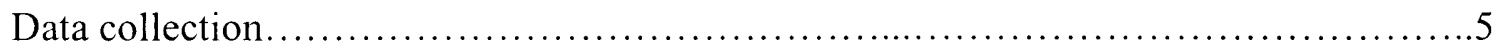

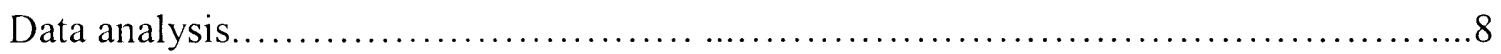

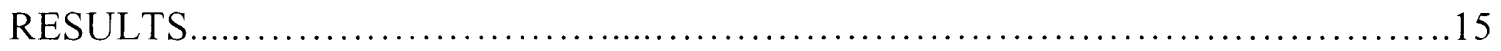

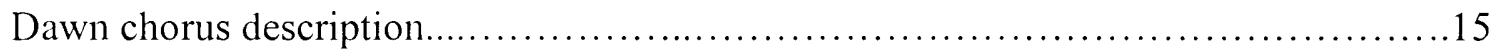

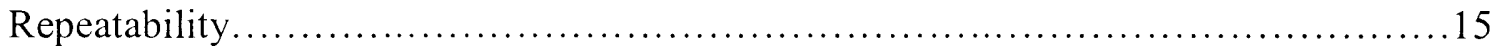

Geophysical variables........................................................ 17

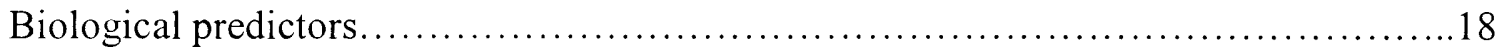

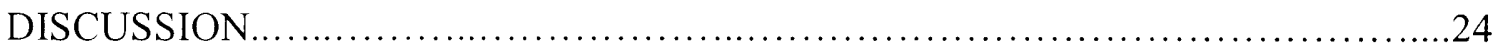

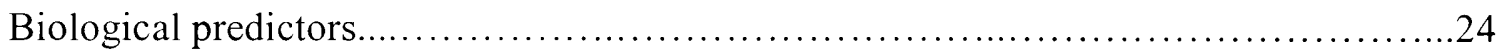

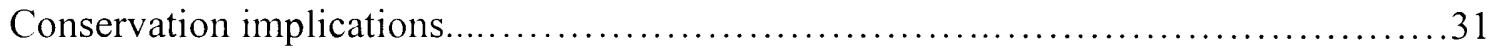

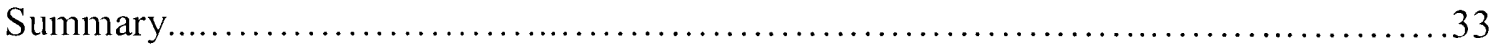

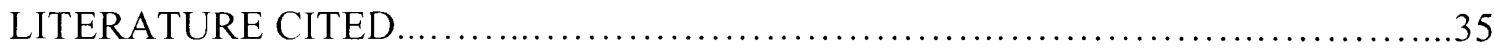

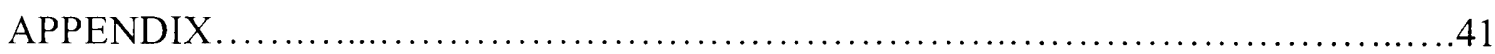




\section{LIST OF FIGURES}

FIGURE

PAGE

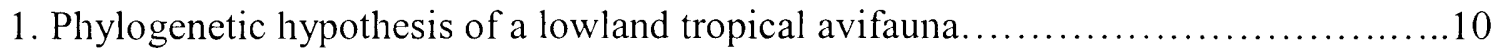

2. Contrasts in relative eye size vs. foraging height............................... I2

3. Species accumulation and light intensity vs. minutes of dawn ....................13

4. Time of first song in 29 species of passerines................................. 17

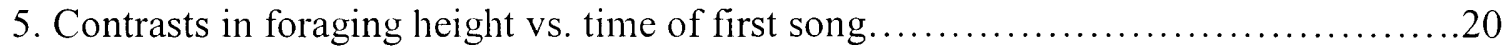

6. Inverse relationship between foraging height and time of first song $\ldots \ldots \ldots \ldots \ldots \ldots \ldots 21$

7. Contrasts in relative eye size vs. contrasts in first song............................23 


\section{LIST OF SYMBOLS}

$$
\begin{aligned}
& \mu \mathrm{m}=\text { micromole } \\
& \mathrm{m}=\text { meter } \\
& \mathrm{mm}=\text { millimeter } \\
& \mathrm{nm}=\text { nanometer } \\
& \mathrm{km}=\text { kilometer } \\
& \mathrm{kHz}=\text { kilohertz } \\
& \mathrm{EST}=\text { Eastern Standard Time } \\
& \mathrm{d}=\text { day } \\
& \mathrm{h}=\text { hours } \\
& \mathrm{min}=\text { minutes } \\
& \mathrm{s}=\text { seconds } \\
& \mathrm{C}=\text { Celsius } \\
& \begin{array}{l}
\mathrm{S} \\
n=\text { sample size }
\end{array} \\
& \mathrm{df}=\text { degrees of freedom } \\
& t=t \text {-value } \\
& z=z \text {-value } \\
& F=F \text {-value }
\end{aligned}
$$




\section{INTRODUCTION}

SONG Functions as a mechanism for mate attraction and territory defense in numerous bird species. The concentration of song at dawn (i.e., the dawn chorus) is notable for its ubiquity across habitats, geographic zones and taxa (Allen 1913, Wright 1913, Taylor 1929, Allard 1930, Leopold and Eynon 1961, Thomas et al. 2002, reviewed in Staicer et al. 1996). Research on the dawn chorus has focused on Oscine passeriforms. In contrast, the equally vocal Suboscines have received little attention in the song literature (Morton 1996). Furthermore, Suboscines abound in the Neotropics and it is unclear whether the well-known temporal sequence to dawn song exists outside the holarctic (Kroodsma et al. 1996). Anecdotal accounts suggest that many non-passerine taxa in the Neotropics also have peaks in vocal output at dawn, including motmots (Momotidae), toucans (Ramphastidae), galliformes and tinamous (Tinamiidae) (Sick 1993, Staicer et al. 1996, Davies 2002). Our understanding of the functional significance of the dawn chorus is based primarily on north temperate Oscines and could thus benefit from studying the phenomena as it relates to tropical systems.

Visual capacity hypothesis.- Regardless of latitude, the dawn chorus appears to be most intense when light levels are changing at the highest rate (Staicer et al. 1996). Less obvious are the reasons driving the correlation between light and song. Armstrong (1963) suggested that birds postpone singing until light-mediated activities such as territorial defense and courtship can be performed profitably. He went on to predict that larger-eyed birds should begin to interact at lower light intensities, as evidenced by an earlier start to dawn singing. Thomas et al. (2002) provided the first empirical evidence supporting the hypothesis by comparing phylogenetic independent contrasts in eye size 
and the time of first song in several bird communities in Europe. Increases in eye size were inversely associated with light intensity at first song, presumably because more photons of light per unit time enter larger eyes thereby increasing visual sensitivity. It is easy to imagine how light mediates activities associated with visual communication, but Armstrong's explanation is much less obvious as to why light should be critical for acoustic communication. The fact that some diurnal species tend to broadcast in complete darkness (i.e., tinamous, nightingales etc.,) suggests that, in at least some cases, acoustic signaling may be a behavior alternative mutually exclusive of visual communication. Although having a larger eye may enable a bird to see at lower light intensities, this does not in itself explain how light mediates acoustic communication. Inefficient foraging.- Kacelnick (1979) furthered the understanding by showing that foraging only becomes profitable in captive Great Tits (Parus major) when light levels reach the point where the dawn chorus in this species typically ends. His experiment was important because it provided a conceptual bridge between activities important to reproductive fitness (i.e., foraging), dawn song and gradually increasing light levels. Kacelnick and Krebs (1982) formalized the hypothesis suggesting a link between foraging and ultimate causes of the dawn chorus. However their model came short of showing how foraging efficiency relates to the staggered start to singing each morning and no one has provided any evidence from foraging attributes of wild birds. Nonetheless, their hypothesis when combined with Armstrong's, gains plausibility. This hypothesis would state that birds' visual capability affects the ability to forage in dim light and differences in visual capability should cause a staggered start to foraging across 
species. It continues that singing is an advantageous behavioral alternative in dim light and as a consequence should produce a staggered start to singing as well.

Visual capacity in dark habitats.- While visual capability clearly should affect a bird's ability to see and perhaps sing at dawn, no one has compared microhabitat light environments to singing onset in different species (Leopold and Eynon 1961, Staicer et al. 1996). Light environments should also be important to song onset, because this likely affects, as should pupil diameter, the number of photons per unit time entering the eye. Perhaps in no above ground, terrestrial ecosystem are microhabitat differences greater than in broad-leafed, epiphyte-laden, humid tropical forests, where light intensity attenuates logarithmically with distance beneath the canopy (Pianka 2000). This ambient light hypothesis combined with visual capacity, would predict that large-eyed birds in the canopy sing earliest because they will begin to forage earlier than understory birds with small eyes.

Predation hypothesis. - Foraging efficiency provides a plausible explanation for why singing ceases at a particular light level, but hypotheses concerning the dawn chorus have fallen short of explaining why species should not sing earlier than they do (Hutchinson 2002). Selection on animal signals is likely to be greatest when significant costs are involved (Endler 1992) and the previous studies mainly describe opportunity costs (i.e, not foraging or not singing). Evidence for direct costs associated with singing earlier, come from Krams (2001) who showed that singing might reveal the position of a bird to its predators. While more evidence is needed for the importance of this during dawn, this observation may be compatible with the visual capability hypothesis (Thomas 
et al. 2002), if relatively larger-eyed canopy birds are able to detect predators at lower light levels, and as a consequence, safely vocalize sooner.

In summary, evidence so far suggests that visual capacity interacts with light in scheduling the onset to singing. The evolving hypothesis states that that individuals should seek to minimize costs of predation by not singing earlier than their visual capacity safely permits, while at the same time maximizing vocal output before diminishing marginal returns of continued singing are surpassed by the benefits of lightmediated foraging.

In order to explore these hypothesized relationships, I studied the dawn chorus in a phylogenetically diverse ensemble of birds from a humid tropical forest in lowland Ecuador in order to: (1) test if the temporal sequence to dawn song is repeatable in the tropics; and (2) investigate the role of light in scheduling social communication. I tested the visual capability hypothesis (see Thomas et al. 2002) by comparing eye size estimates with first song, predicting that large-eyed birds should sing earlier and at lower light levels than birds with small eyes. I also tested the hypothesis that ambient light affects the scheduling of the onset of singing, by comparing the foraging height of species with the times and light intensities at first vocalization. I predicted that birds in the canopy should sing earlier and at lower light levels, because they receive more light sooner (i.e., they see better in dim light). 


\section{METHODS}

\section{Data Collection}

Study site.- Data was collected on the dawn chorus at the 1000 ha Tito Santos Biological Station in the province of Manabi, lowland western Ecuador $\left(80^{\circ} 12^{\prime} \mathrm{W}, 0^{\circ} 11^{\prime}\right.$ S), within $5 \mathrm{~km}$ of the Pacific Ocean. The rolling topography is covered with remnants of deciduous dry tropical (20\%), semi-deciduous moist tropical (60\%) and evergreen humid tropical (20\%) forest. Precise climatological data from the study site are not available, but annual precipitation is thought to average ca. $1500 \mathrm{~mm}$, with $99.9 \%$ recorded between December and June. Temperatures in the region typically range between $18^{\circ}$ and $33^{\circ} \mathrm{C}$ at sea-level (1NAMHI, 1996).

Temperature measurements.- Ambient temperature was measured $\left( \pm 1^{\circ} \mathrm{C}\right)$ with Hobo H08 (Onset Computer Corp., Bourne, MA) sensors and logged at 10 min intervals throughout the study period. The sensor was mounted $3 \mathrm{~m}$ above the ground, protected from rain and direct sunlight by a wooden roof, but otherwise exposed to surface wind. The sensor was located in a secondary forest clearing at $50 \mathrm{~m}$ elevation.

Irradiance measurements.- Irradiance between 400-700 nm was measured $( \pm 5 \%)$ every minute during dawn recordings using two LI-190S quantum sensors (Licor, Lincoln NE) with a sensitivity of approximately $0.001 \mu \mathrm{mol} \mathrm{s} \mathrm{m}^{-1}$ and a LI-1400 data logger (Licor). Means were calculated from the two sensors in order to reduce calibration error. The light sensors were located at the same site as the temperature sensor described above, with the exception that the light sensors were located on a level plane 3 $\mathrm{m}$ above the ground, $25 \mathrm{~m}$ from forest but otherwise exposed to the open sky. Initial irradiance levels at twilight were below the detection threshold of the sensors; therefore 
on approximately $1 \%$ of the observations of first song light readings were absent and assumed to equal zero. For logistical reasons light levels were only measured on 15 of 25 census days.

Bird community.- I collected visual and acoustic observations of species of birds occurring in the reserve and surrounding areas during two visits between 8 May - 10 June 2002 and 23 January - 3 March 2003 (ca. 10 weeks, or 600 person-hours). I observed at least 238 species of birds in the region, distributed across 19 orders, 49 families and 181 genera (Append. I). Species associated with aquatic habitat including mangrove remnants comprised 26 species. Of the terrestrial species, four were transcontinental migrants. Sixty-five species were associated with secondary forest and pastures, while the remaining 114 occurred mainly in mature forest (i.e., core forest avifauna sensu Remsen 1994). Of these, 70 species vocalized during the survey (Append. I), thus majority may have been breeding.

Foraging height.- Foraging height of birds was estimated following Remsen and Robbinson (1990). Flagging tape placed on tree limbs at 5, 10 and $15 \mathrm{~m}$ above the ground was used as a reference frame for practice. Vertical position of birds (within $1 \mathrm{~m}$ ) was estimated between $0800-1000 \mathrm{~h}$. Foraging height has been argued to be an important species-specific trait in tropical forest birds (Pearson 1971, Bell 1982, Walther 2002). In this study foraging height was a repeatable trait in 37 species $(F=11.7387$, df $=36,158, P<0.0001, r=0.6735)$.

Sampling design-. The dawn chorus was recorded at 6 mature forest sites $(>200$ $\mathrm{m}$ apart), which were evenly spaced along a 50-350 m elevation gradient that crossed the transition from semi-deciduous moist to humid evergreen tropical forest. Recordings 
were made between 21 January and 27 February 2003 on 4 or 5 mornings per site between 0540-0545 and 0740-0745 h (Eastern Standard Time, depending on local sunrise), with sampling dates evenly spaced across the study period. 1 sampled dawn choruses during the wet season and thus the breeding season for many bird species in western Ecuador (Marchant 1959, Berg 2001, pers. observ.). Although a concerted effort to estimate breeding was not attempted, casual observations revealed evidence of breeding in at least 19 species during the study period.

Vocalization measurements.- Recordings were made with a MKH20 omnidirectional microphone (Sennheiser, Wedemark, Germany) mounted $1.5 \mathrm{~m}$ above ground. A Sony TC-D5 Pro II recorder was used to record on Type II cassette tape (TDK SM and SA). Recordings were synchronized at the beginning of nautical twilight each day, i.e. when the sun was $12^{\circ}$ beneath the horizon, and continued for 120 min. Nautical twilight was determined using latitude-longitude coordinates and the Astronomical Applications website of the U.S. Naval Observatory (http://aa.navy.gov).

Morphological measurements.- Eye diameter (based on eyes removed from wet preserved specimens) and body mass were obtained from published data (Ritland 1982). Additional eye diameter data were obtained following Thomas et al. (2002) and taken from study skins housed in the collections of the Museum of Natural Science of Louisiana State University, Smithsonian Museum of Natural History, Washington D.C. and the Philadelphia Academy of Natural Sciences. Only specimens with body weight were used. Since the globe of the eye is partially concealed by the orbit, measurements from Ritland (1982) were larger than those from skins and thus the latter (Y) were standardized with the wet preserved specimens $(\mathrm{X})$ for six species using the following 
regression equation: $\mathrm{Y}=-0.26( \pm \mathrm{SE} 0.066)+1.035( \pm \mathrm{SE} 0.062) \mathrm{X}(F=278.43, \mathrm{df}=$ $\left.1,15, P<0.0001, r^{2}=0.949\right)$. Eye size and body mass measurements were highly repeatable within species (eye: $F=25.60, \mathrm{df}=32,65, P<0.0001, r=0.8939$; body: $F=$ 183.03, df $=31,64, P<0.0001, r=0.9841)$.

Data Analysis

Time of first song.- Analog recordings were digitized with an Audiophile model 2496 (M-Audio, Arcadia, California) sound card and Cool Edit Pro (Adobe Systems Inc., San Jose, California) software and archived as WAV files on compact disk (Taiyo Yuden). Digital recordings were low-pass filtered (12.5 kHz, 8 pole analog Butterworth) to increase signal-to-noise ratio, while sonograms/recordings were scored for the time of first vocalization $( \pm 1 \mathrm{~min})$ for each diurnal species $(n=3000 \mathrm{~min})$. A digital database of species repertoires was created to aid in the identification process (ca. 1060 recordings of 133 species). Identifications were made possible by my uninterrupted residency in the region between 1991-2001. Recordings were also compared with those published from the region (Jahn et al. 2002, Coopmans et al. 2004). Doubtful recordings or those unidentifiable by the author were sent to an expert on vocal repertoires of the region, Dr. Niels Krabbe (Zoological Museum of Copenhagen) for a second opinion.

Focal species.- At least 91 resident, diurnal species vocalized during the census of which 21 were associated with secondary vegetation. Of the 70 resident forest species that vocalized, 8 were only recorded once. Of the other 62 species, the following were excluded from analysis because of their nomadic habits: Gymnopithys leucaspis, Dendrocincla fuliginosa. Microrhopias quixensis, Myrmotherula fulviventris and Herpsilochmus rufimarginatus. 1 based this designation on personal experience, 
descriptions in Willis (1972), Willis and Oniki (1978), Munn and Terborgh (1979), and Terborgh et al. (1990). Because the remaining 57 species (49 genera) were considered a more territorial subset of the core avifauna, singing observations of these species $(n=$ $17,350)$ were thought to contain a representative sample of time of first vocalization in this bird community (see Append. I)

Phylogeny:- Because similar species may exhibit the same trait through common ancestry, I employed Felsenstein's method (1985) of calculating phylogenetic independent contrasts. Sibley and Ahlquist (1990) provided the basis for the topology and branch length information for 41 of the 49 genera presented in Figure 1. This source did not provide species level resolution; therefore, in the case of congeneric taxa, one of the sister species was excluded from analysis based on the following criteria: smaller sample size of vocalizations, or absence of observations of foraging height or morphometric measurements. Branch length was assumed equal to that of the most closely related taxa for 8 genera not included in Sibley and Ahlquist (1990). Tinamus was considered sister to Crypturellus; Pyriglena to Myrmeciza (Sibley and Alquist 1990, Ridgely and Greenfield 2001); Cyanocompsa to Pheucticus; Arremon to Arremonops; and Parula to Basileuterus (Ridgely and Greenfield 2001). Onychorhynchus, Cnipodectes and Lophotriccus were grouped into a polytomy based on Birdsley's (2002) grouping of these genera into the Flatbill-Tody-tyrant assemblage. Lathrotriccus, an undescribed genus at the time of Sibley and Ahlquist's work, was grouped according to Birdsley (2002) in the Elaenid-Empidonax assemblage and was assumed to form a polytomy with the Myiarchus, Flatbill-Tody-tyrant, and Manacus assemblages. Although 


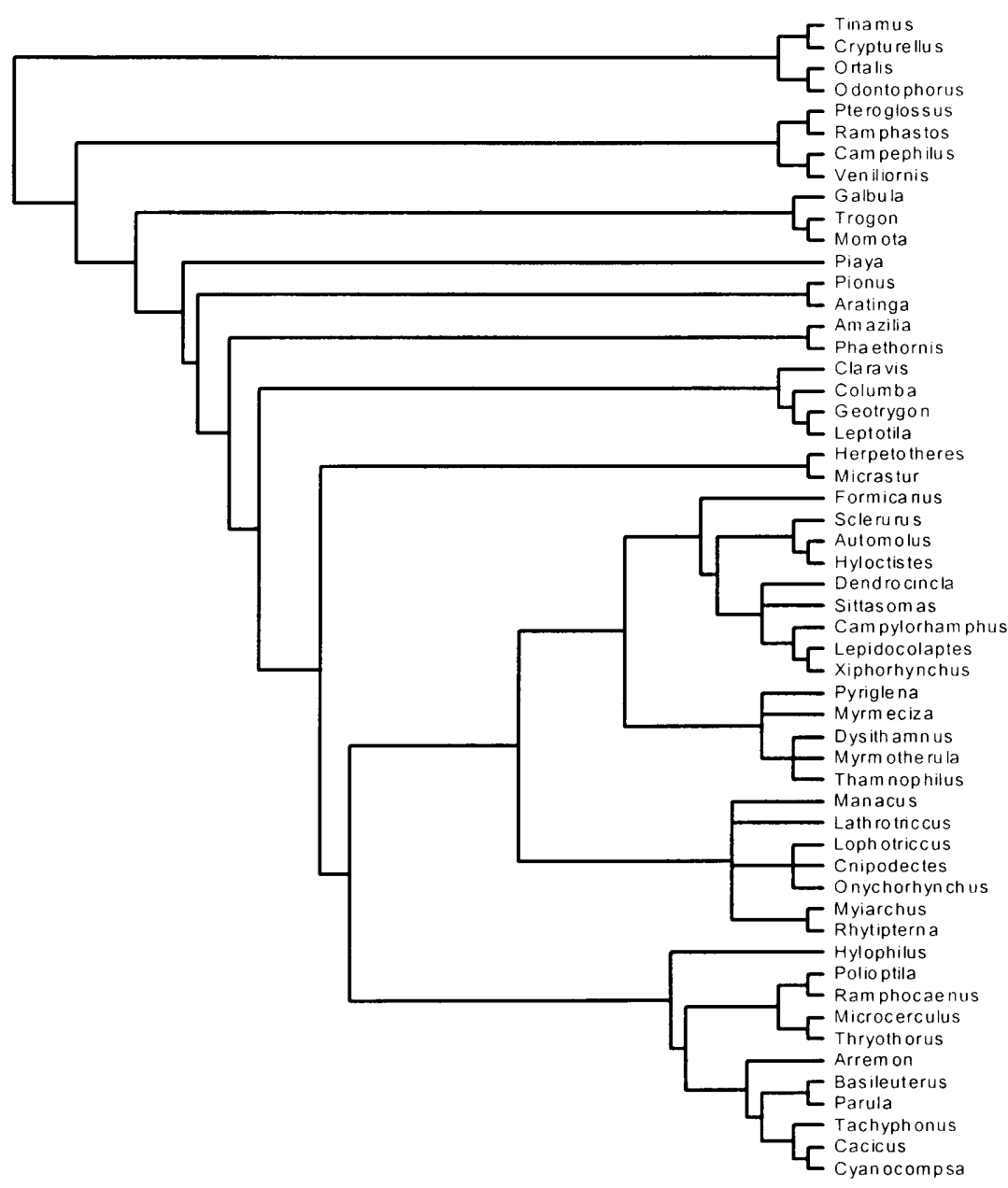

Fig. 1. Phylogenetic hypothesis of a lowland tropical avifauna based on Sibley and Ahlquist (1990).

Manacus (Pipridae) is by some considered basal to the Tyrannidae (Chesser, in-press 2004, Irestedt et al. 2002) evidence is equivocal (Birdsely 2002). I chose to follow Sibley and Ahlquist (1990) and grouped this species in a polytomy with the other major branches of the Tyrannidae, in order to preserve branch length information for the remaining taxa. While I used only one topology (and subsets therein), analyses were 
conducted with variable and then with equal branch length information to allow for comparison. However, owing to the larger number of assumptions involved with including variable branch length information, and the fact that the results did not vary significantly, I followed Russo et al. (2003) and report only results assuming equal branch length.

Statistical Analysis.- All statistical analyses were performed using SAS (v. 9). Repeatability of the time of first song was determined using variance components analysis (PROC NESTED) following Lessells and Boag (1987). I compared correlation coefficients using Fisher's $z$ transformation (Zar 1999). I used general linear models (PROC GLM) to test the relationship between time of first song (expressed in minutes of nautical twilight) and uncorrelated explanatory variables. When explanatory variables were correlated, I used residuals to avoid multicollinearity. I assessed the model fit by analyzing residuals for evidence of heteroscadesticity and employed log-transformations as indicated. I calculated phylogenetic independent contrasts in time and light at first song and other species traits using CAIC software (Purvis and Rambaut 1995) and analyzed output using general linear models with regression lines forced through the origin. For all regressions using contrasts I checked for violations of model assumptions (Purvis and Rambaut 1995). 
I conducted an analysis of covariance to determine degree of multicollinearity in the data set. Contrasts in eye diameter scaled with body mass forming a typical allometric relationship (slope $=0.22)$. This relationship was slightly stronger in the passerine assemblage, but this could be due to smaller sample size in the non-passerines. Because eye size and body mass are confounded, and each has been argued to affect timing of dawn song (Thomas et al. 2002), they were separated in linear models to determine the relationship between residual eye size and foraging height. Contrasts in relative eye size showed no relationship with contrasts in foraging height (for passerines: $F=1.03, \mathrm{df}=1,17, P=0.33, r^{2}=0.06$, Fig. 2 ) and were thus combined in models predicting first song.

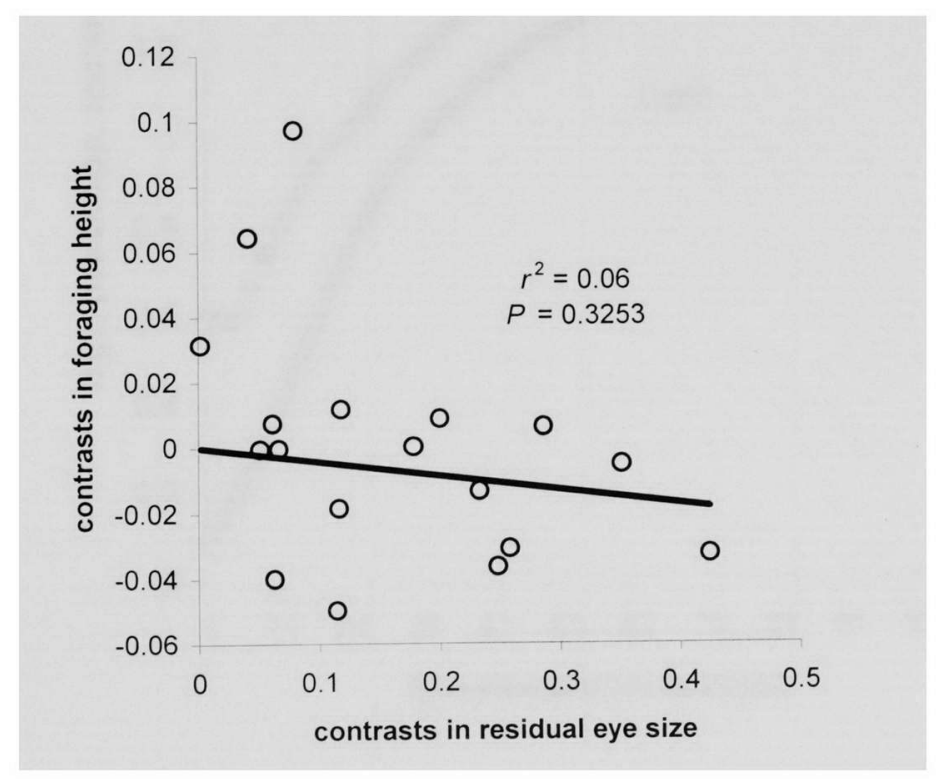

Fig. 2. Contrasts in eye size (relative to body size) as a function of contrasts in foraging height in 18 contrasts of passerines from a lowland tropical forest in Ecuador (29 species, Jan - Feb 2003). Lack of correlation suggests both variables can be used in multiple predictor models. 
Definition of dawn song.- To control for normal day-time singing, I included only observations of singing during the first 100 minutes of nautical twilight. This was based on an analysis of species accumulation per minute of census and light intensity per minute plotted against time of day at one site for the entire 120 minutes of data ( $n=5 \mathrm{~d}$, Fig. 3). The data set suggests that both the rate of species' participation in the dawn chorus and light intensity leveled-off at approximately 100 minutes after the beginning of twilight (or ca. 85 min of civil twilight, Fig. 3).

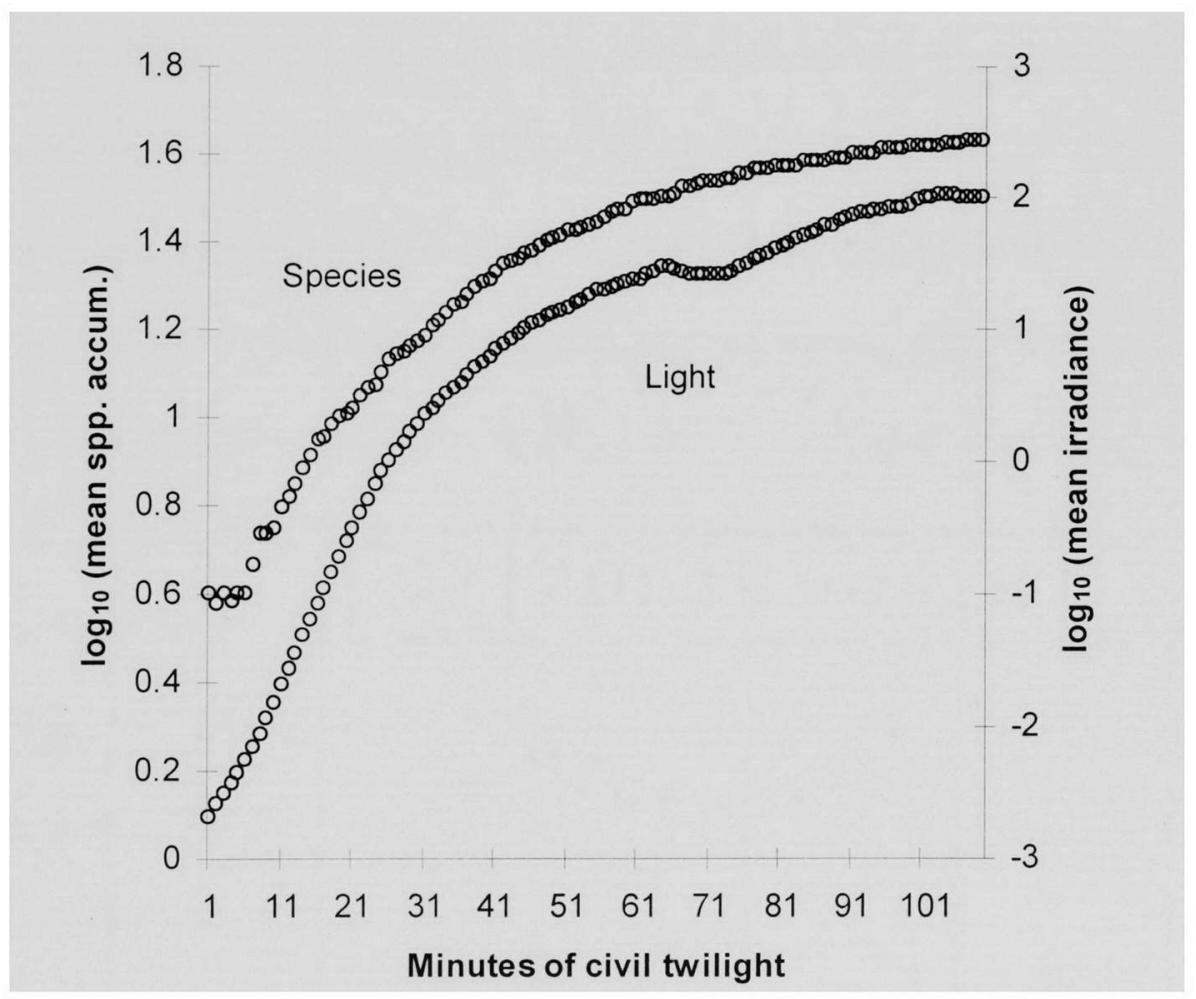

Fig. 3. Mean species accumulation based on song and light intensity per minute at the same locality on 5 days in a humid tropical forest of lowland Ecuador (Jan-Feb 2003). 
Temperature and light.- Overnight minimum temperature preceding each day was calculated and incorporated into the data set. For comparison, temperature data were adjusted by increments of $0.4^{\circ} \mathrm{C}$ depending on the elevation of the site (range in study site $=300 \mathrm{~m}$ ), because temperature declines by roughly $1^{\circ} \mathrm{C}$ for each $150 \mathrm{~m}$ increase in elevation (Campbell and Norman 1998). Light measurements made each minute were incorporated for all observations of first song. 


\section{RESULTS}

Dawn chorus description.- Fifty-seven species of birds vocalized consistently throughout the study period. The mainly forest species were distributed across 10 orders, 24 families and 49 genera (Ridgely and Greenfield 2001, Append. I). Mean time of first song varied widely across species and ranged from the Collared Forest-falcon (Micrastur semitorquatus), which began vocalizing 14 minutes ( $+/$ - SE 1.89) after the beginning of nautical twilight ( $n=7$ mornings) or when light intensity was $0.0825 \mu \mathrm{mol} \mathrm{s}{ }^{-1} \mathrm{~m}^{-2}$, to the Scaly-throated Leaftosser (Sclerurus guatemalensis) which did not begin to sing until 82 minutes (+/-SE 6.13) after the beginning of nautical twilight ( $n=6$ mornings,) or when light intensity reached $63.4 \mu \mathrm{mol} \mathrm{s} \mathrm{m}^{-1}$. Passerine species outnumbered all other orders combined, and tended to be dominated by species belonging to the Suboscine branch (Append. I, Fig. 4.). The Suboscines tended to sing earlier (mean of $46 \mathrm{~min}+/-\mathrm{SE}=$ 4.5127) than the oscines (mean of $61 \mathrm{~min}+/-\mathrm{SE}=3.189$; two-sample test of means, $t=$ 2.699, $P=0.0120$, Fig. 4) and at lower light intensities (mean of $7.75 \mu \mathrm{mol} \mathrm{s}^{-1} \mathrm{~m}^{-2}+/-\mathrm{SE}$ 3.02 vs. $13.03 \mu \mathrm{mol} \mathrm{s}^{-1} \mathrm{~m}^{-2}+/-\mathrm{SE} 2.37$, respectively), although the latter was not significant $(t=1.281, P=0.2112)$. Species commonly observed in forest but conspicuously absent from recordings belonged to the families Accipitridae, Bucconidae and Apodidae (Append. 1).

\section{RePEATABILITY}

Time and light.- Time of first song was highly repeatable within species (Table I). Observations nested within species explained between 48 and $63 \%$ of variation in time at first song. Between 57 and $70 \%$ of the variation in light intensity at first song could be explained with species. Light was generally a better predictor of singing 
schedules than was time (Table I). Passerines had higher repeatability values than did non-passerines, although the difference was not significant $(t=0.648, \mathrm{P}>0.50)$.

Table I. Results of analysis of repeatability of time and light at first song for different taxonomic groups. The far right-hand collumn provides results of comparisons of repeatabilities using Fisher's z-test.

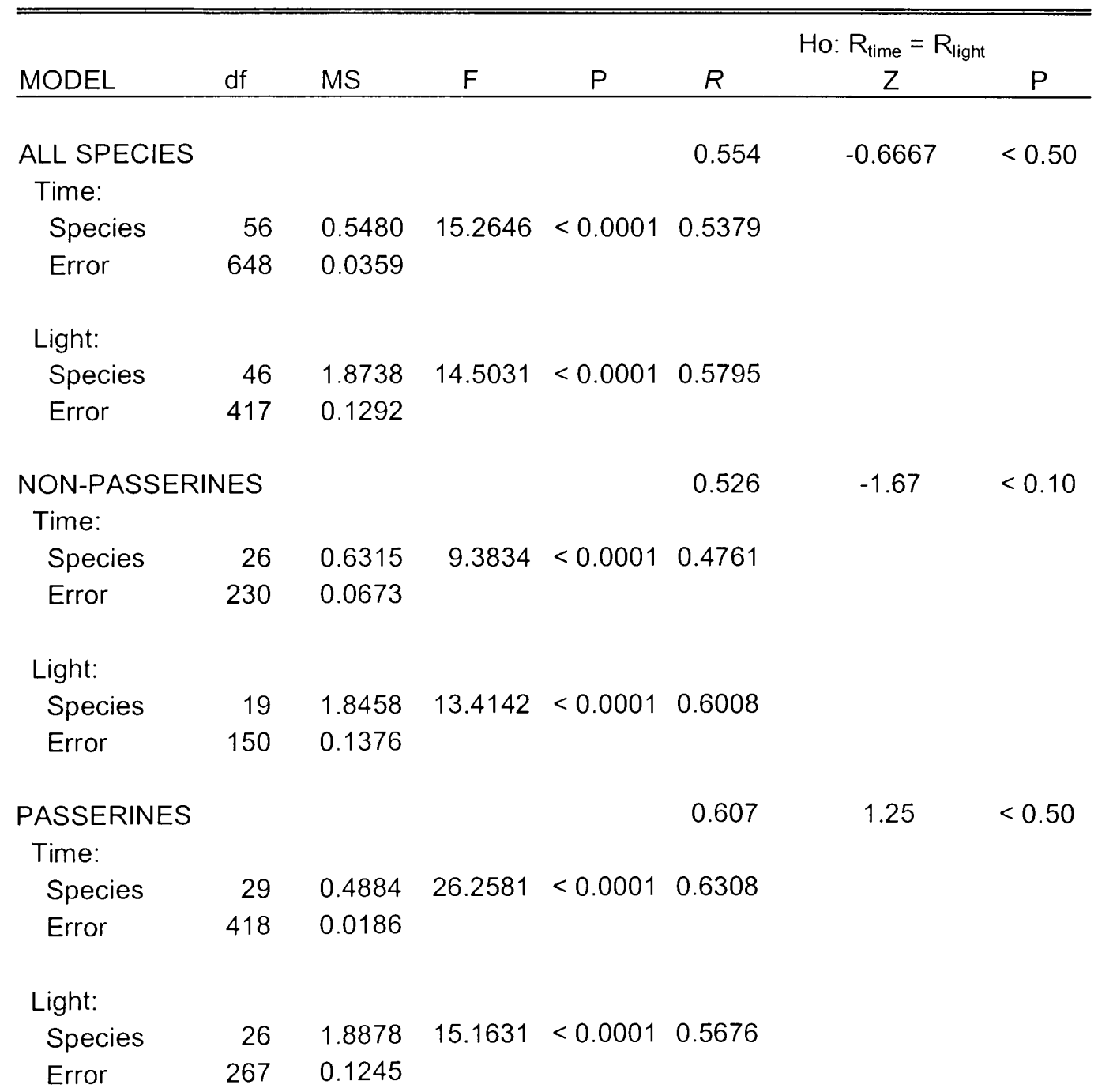




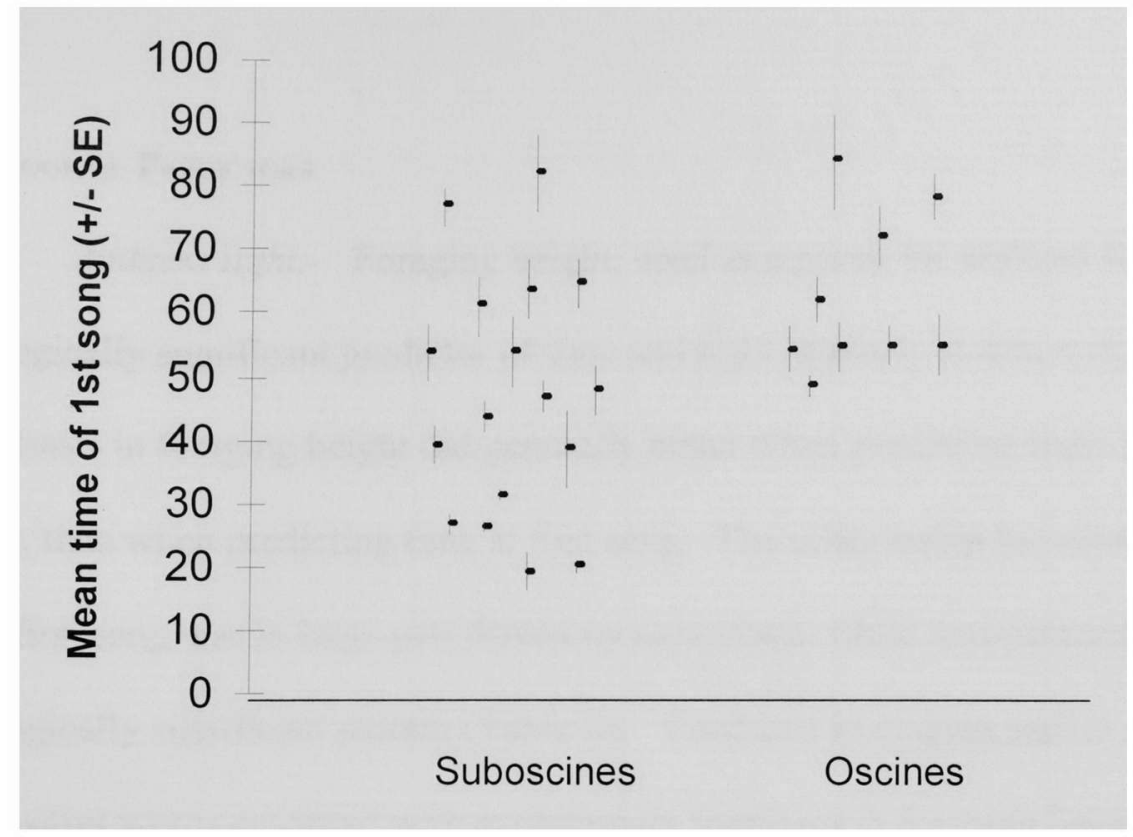

Fig. 4. Mean time of first song in 29 passerine species from a humid tropical forest in lowland Ecuador. Means were pooled from observations across six sites on 25 days and are grouped by suborder (Jan-Feb 2003). Suboscines sang significantly earlier than Oscines.

\section{Geophysical Variables}

Temperature and elevation.- Overnight minimum temperature ranged over $3^{\circ} \mathrm{C}$ and never fell below $21^{\circ} \mathrm{C}$. Not surprisingly, given this variation, minimum overnight temperature, whether or not adjusted for elevation, showed no statistical effect on the timing of first song. This was the case for all or species (adjusted temperature for time: $F$ $=3.21, \mathrm{df}=1,462, P=0.0739, r^{2}=0.007$ ) as well as for the passerines (adjusted temperature for time: $\left.F=2.43, \mathrm{df}=1,292, P=0.12, r^{2}=0.01\right)$. Similarly, elevation of recording sites had no effect on singing schedules (for time in non-passerines: $F=0.90$, $\mathrm{df}=1,165, P=0.3444, r^{2}=0.005 ;$ and for light in passerines: $\mathrm{df}=1,292, F=0.61, P=$ $\left.0.4366, r^{2}=0.002\right)$. 
Biological Predictors

Ambient light.- Foraging height, used as a proxy for ambient light, was a biologically significant predictor of time and light intensity at first song (Fig. 5, Table II). Contrasts in foraging height did generally better when predicting light intensity at first song, than when predicting time at first song. The relationship between foraging height and first song was in large part driven by passerines, while non-passerines showed no biologically significant pattern (Table II). Contrasts in singing earlier and at lower light intensities were correlated with evolutionary increases in foraging height. At lower taxonomic divisions within the Passeriformes, the relationship strengthened. A negative correlation between contrasts in foraging height and time of first song was found for Suboscine species $\left(F=10.27, \mathrm{df}=1,13, P=0.0075, r^{2}=0.46\right.$; see also Fig. 6). Contrasts in the Oscines or in lower taxonomic groups could not be analyzed because of small sample size. Controlling for phylogeny only marginally improved models predicting first song. When contrasts were ignored, the relationship between foraging height and time of first song was also stronger in lower taxonomic divisions. Figure 6 shows that the relationship between foraging height and time of first song had an r-square of 0.32 for 29 passerine species (vs. $r^{2}=0.35$ in analysis of contrasts). The top graph shows that both Suboscines and Oscines had greater r-square values when analyzed separately than when pooled. Similarly, in the bottom graph, two important groups of closely-related taxa (tyrant flycatchers and ovenbirds-antbirds) also had larger r-square values than when all passerines were considered. 
Table II. Analysis of variance of contrasts in time and light intensity at first song as a function of foraging height for different taxonomic groups.

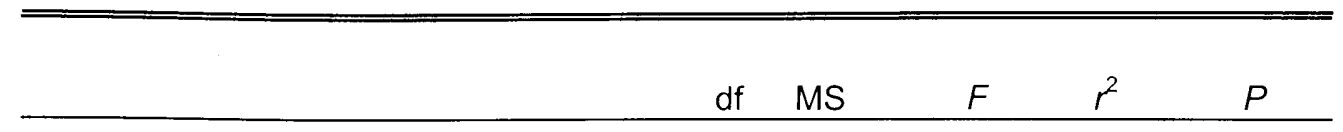

ALL SPECIES

Time

$\begin{array}{lccccc}\text { Height } & 1 & 0.0289 & 2.69 & 0.08 & <0.1121 \\ \text { Error } & 29 & 0.0108 & & & \end{array}$

Light

$\begin{array}{lrrrrr}\text { Height } & 1 & 0.2395 & 5.32 & 0.15 & <0.0284 \\ \text { Error } & 29 & 0.045 & & & \end{array}$

NON-PASSERINES

Time

$\begin{array}{lcccc}\text { Height } & 1 & 0.0085 & 0.61 & 0.05<0.4508 \\ \text { Error } & 11 & 0.0139 & & \end{array}$

Light

$\begin{array}{lcccc}\text { Height } & 1 & 0.0280 & 0.76 & 0.06<0.4008 \\ \text { Error } & 11 & 0.0367 & & \end{array}$

PASSERINES

Time

$\begin{array}{lccccc}\text { Height } & 1 & 0.0612 & 9.01 & 0.35 & <0.008 \\ \text { Error } & 17 & 0.0068 & & & \end{array}$

Light

Height

Error

$\begin{array}{ccccc}1 & 0.4225 & 10.38 & 0.38 & <0.005 \\ 17 & 0.0407 & & & \end{array}$



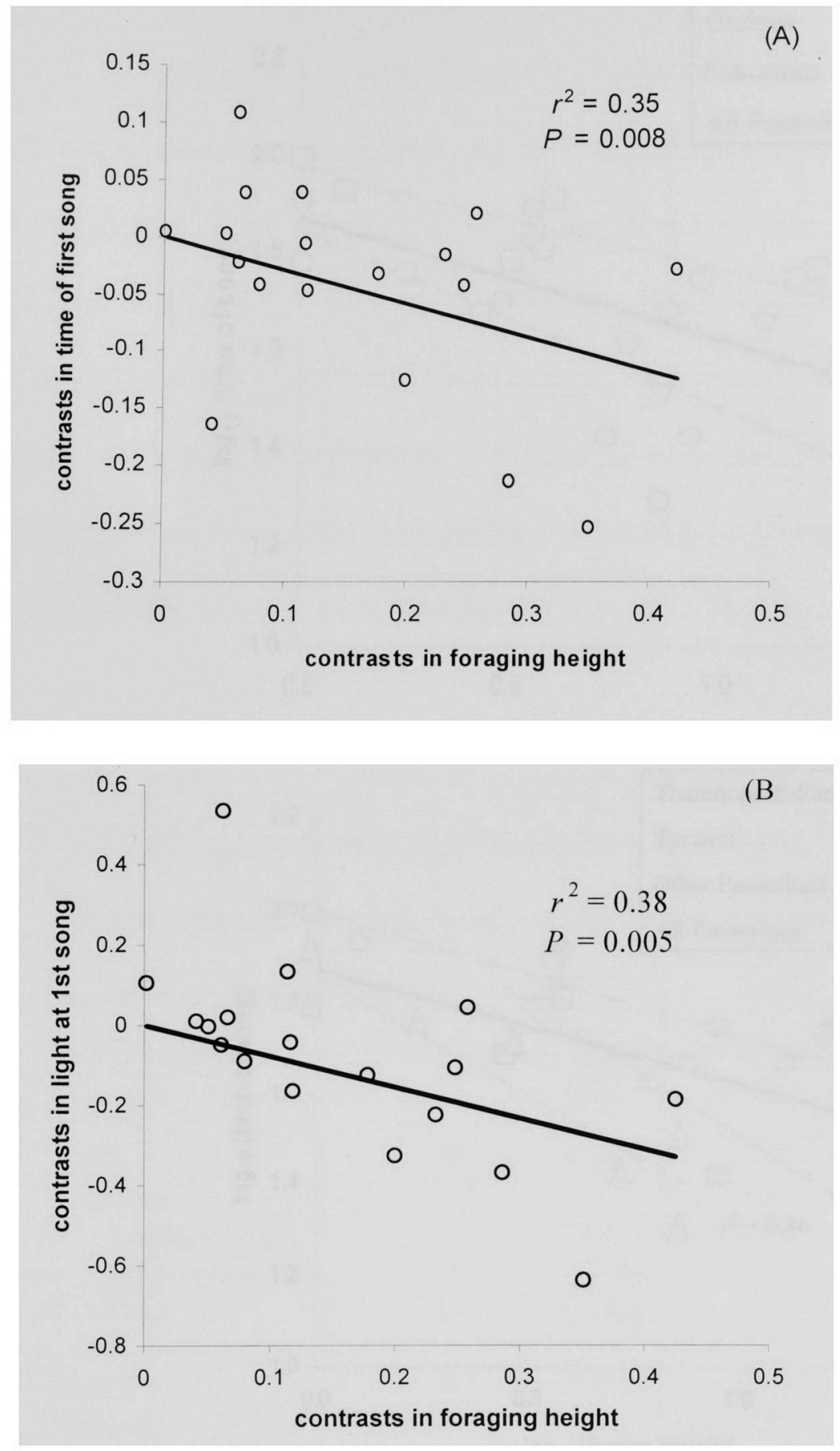

Fig. 5. Relationship between contrasts in foraging height and first song in passerines from a lowland tropical forest in Ecuador. (A) Inverse relationship between contrasts in mean foraging height and mean time of first song in 18 contrasts ( 29 species). (B) Inverse relationship between 18 contrasts in mean foraging height as a function of mean light intensity at first song (26 species). 

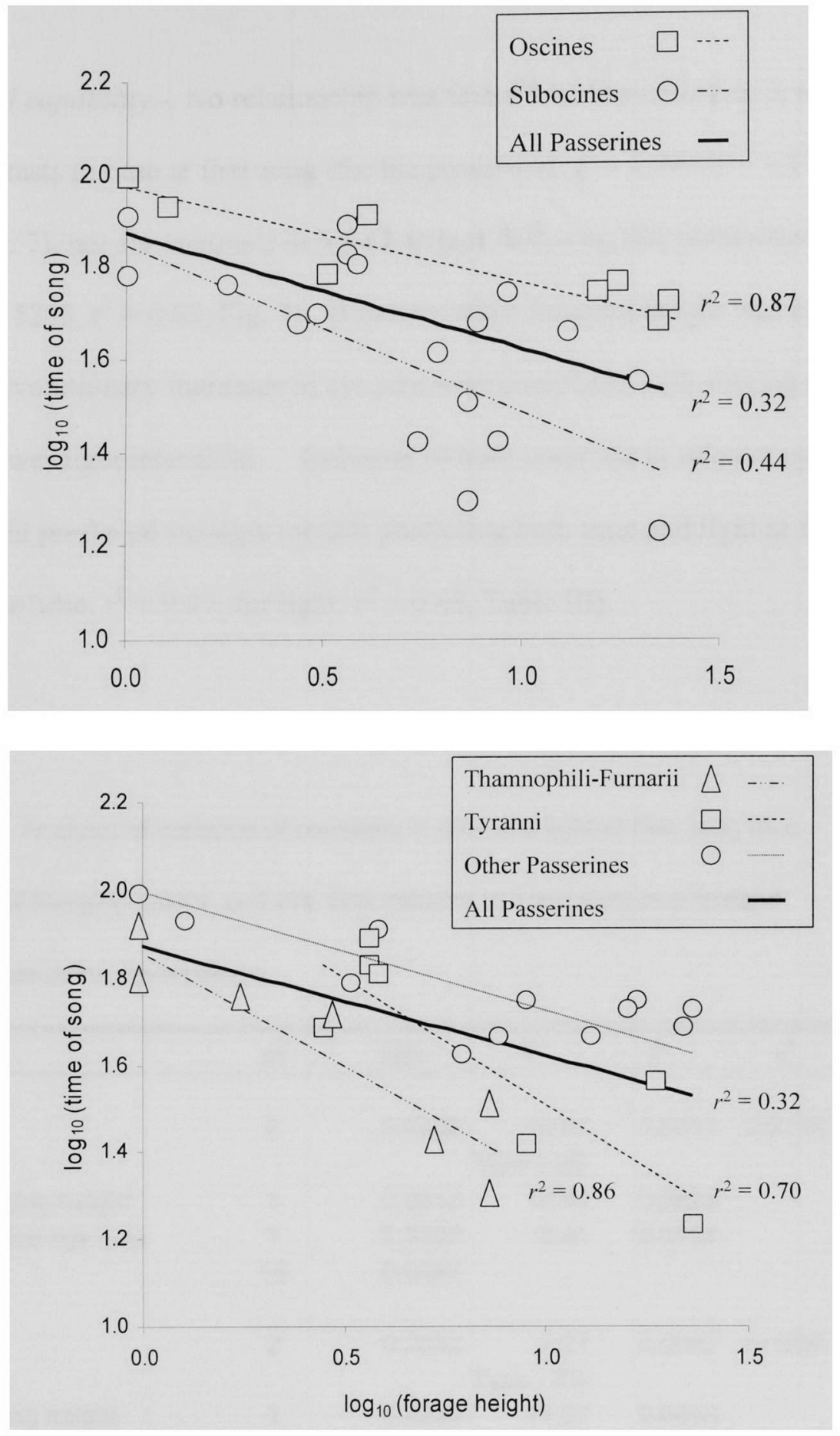

Fig. 6. Top: inverse relationship between foraging height and time of first song in 26 passerine species with symbols showing species belonging to two major branches of the Passeriformes. Bottom: same data but with two closely-related suboscine groups distinguished. Tribes Thamnophili-Furnarii (excluding Dendrocolaptidae) and Tyranni follow Sibley and Ahlquist (1990). 
Visual capability:- No relationship was found between contrasts in relative eye size and contrasts in time at first song (for the passerines: $F=1.94, \mathrm{df}=1,17, P=0.1811$, $r^{2}=0.10$, Fig. 7), nor for contrasts in light levels at first song (for passerines: $F=0.42, \mathrm{df}$ $=1,17, P=0.5255, \mathrm{r}^{2}=0.02$, Fig. 7). However when foraging height was controlled for statistically, evolutionary increases in eye size were correlated with singing earlier and at marginally lower light intensities. Inclusion of both contrasts in relative eye size and foraging height produced stronger models predicting both time and light at first song for passerines (for time: $r^{2}=0.57$; for light: $r^{2}=0.48$, Table III).

Table III. Analysis of variance of contrasts in time and light at first song as a function of foraging height, and eye size (relative to body size) in a lowland tropical passerine assemblage.

\begin{tabular}{|c|c|c|c|c|c|}
\hline & df & MS & $F$ & $P$ & $r^{2}$ \\
\hline TIME & 2 & 0.0505 & 10.67 & 0.0011 & 0.5716 \\
\hline Source: & \multicolumn{5}{|c|}{ Type I SS } \\
\hline Foraging height & 1 & 0.0612 & 12.94 & 0.0024 & \\
\hline Relative eye size & 1 & 0.0398 & 8.41 & 0.0104 & \\
\hline Error & 15 & 0.0047 & & & \\
\hline LIGHT & 2 & 0.2652 & 7.27 & 0.0057 & 0.4759 \\
\hline Source: & \multicolumn{5}{|c|}{ Type ISS } \\
\hline Foraging height & 1 & 0.4225 & 11.57 & 0.0036 & \\
\hline Relative eye size & 1 & 0.1079 & 2.96 & 0.1048 & \\
\hline Error & 15 & 0.0365 & & & \\
\hline
\end{tabular}


(A)
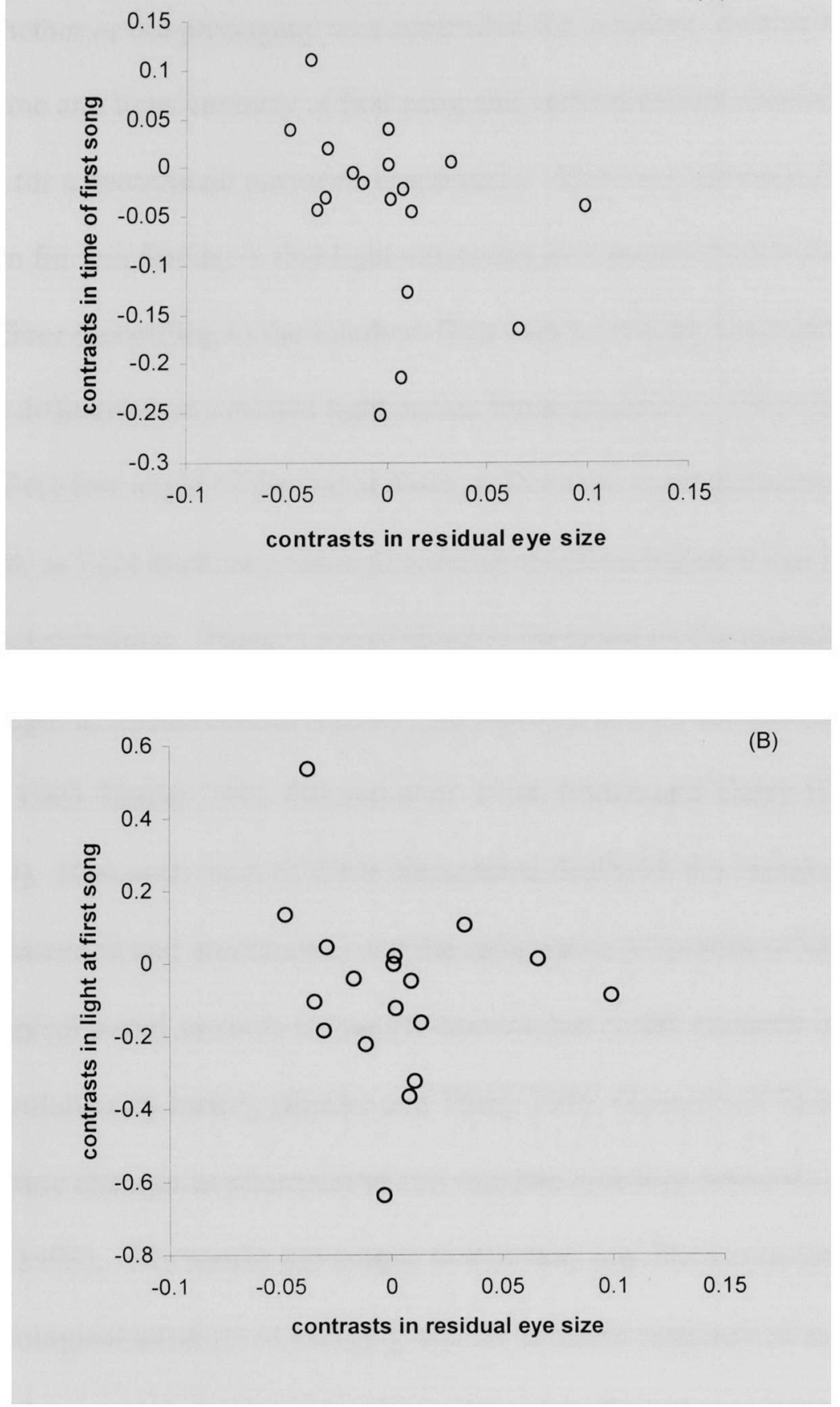

Fig. 7. (A) Contrasts in eye size (relative to body size) as a function of contrasts in time of first song and (B) contrasts in relative eye size as a function of light at first song from passerine assemblages in a lowland tropical forest of Ecuador (Jan - Feb 2003). 


\section{DISCUSSION}

Whether or not phylogeny was controlled for, a robust, inverse relationship between time and light intensity at first song and vertical habitat specialization was delineated for a neotropical passerine community. The most obvious, proximate explanation for this finding is that light attenuates as it passes from the canopy down to the forest floor (according to the Lambert-Beer Law), creating large quantitative and qualitative differences in ambient light across forest strata (Lee 1985, Endler 1993). Because of the low angle of the sun at dawn, seldom are these differences more pronounced, as light must pass through more atmosphere before it can illuminate any particular microhabitat. There is a considerable literature on the quantity and spectral quality of light in forests and its selective pressure on animal communication systems (Marchetti 1993, Endler 1993, Bennett et al. 1994, Endler and Théry 1996, Gomez and Théry 2004). However, most of these discussions deal with the visual capability of receivers (intended and unintended) and the reflectance properties of senders. Effects of light on tropical social systems are poorly-known, but recent research indicates a complex evolutionary history (Endler and Théry 1996, Gomez and Théry 2004) and that seemingly tiny changes in photoperiod can regulate breeding activities including singing (Hau et al. 1998). My results are unique in that they provide a conceptual link between light, an ecological attribute of foraging and the acoustic response of senders.

Environmental variables have been shown to affect the evolution of acoustic signals of animals in a variety of ways. Most studies involving birds have dealt with documenting differences in the physical properties of habitats (Morton 1975, Richards and Wiley 1980), or diel changes in properties (Henwood and Fabrick 1979) and more 
recently how these relate to fitness characteristics (Slabbekoorn and Smith 2002). In most cases, research has focused on how ecological variables, such as vegetation and climate, affect the transmission of acoustic energy. In a broad sense, the findings reported here support these studies, providing evidence that both biotic (foraging strata) and abiotic (light) variables may have helped shape song routines in birds. However, results here are novel in that they show that ecological variables may have influenced acoustic signaling in ways other than through direct interaction between the acoustic energy of the sender and the transmission properties of habitat.

Vertical stratification of birds.- Foraging height has been found to be a speciesspecific trait in several lowland rainforest bird communities (Pearson 1971, Bell 1982, Marra and Remsen 1997, Walther 2002) and results reported here support these findings. However, foraging height may only be indirectly related to singing earlier when viewed in a broader context of reproductive strategy and habitat specialization. Numerous factors affecting the general livelihood of birds may also change in concert with forest height. While it is suggested here that light intensity may be the most obvious of these affecting the scheduling of the onset to singing, other potentially confounding factors include the spectral composition of light (Lee 1985, Endler 1993), evaporation, humidity, temperature, wind (Campbell and Norman 1998), food and predator abundance (Pearson 1971, Terborgh 1980), parasite abundance (Garvin and Remsen 1997, Walther et al. 1999), foliage density and complexity (Pearson 1971, 1975, 1977, Walther 2002), plumage brightness, nest locations (Marchetti 1993, Garvin and Remsen 1997), spectral quality of acoustic signals (Morton 1975) and acoustic broadcast coverage (Henwood and Fabrick 1979, Wiley and Richards 1980, Waide and Narins 1988). Clearly, a complex 
milieu of selective factors change from the canopy to the forest floor, many of which may have had the opportunity to influence reproductive strategies including song.

Habitat specialization and dawn song.- One tenet of species diversity theory is that foliage height diversity predicts the number of bird species at a given site (MacArthur and Wilson 1967). Less obvious are the mechanisms explaining how structural complexity in plant communities relates to reproductive isolation of sympatric bird populations. The vertical distribution of the avifauna in tropical forests has been argued to explain tighter species packing into narrow foraging breadths (Marra and Remsen 1997). On the other hand, song has been shown to be important in mate choice and reproductive divergence (Searcy and Anderson 1986, Searcy and Yasukawa 1996) and the dawn chorus may represent an important opportunity for males to communicate information concerning fitness (Otter et al. 1997). The linkage between reproductive isolation and divergence in temporal characteristics of traits related to reproductive fitness has received little attention (Slabbekoorn and Smith 2002). Numerous ecological and morphological factors likely conspire to restrict optimal foraging and predation defense strategies of individuals, resulting in narrow vertical habitat breadth in species. The ecological characteristics of a particular microhabitat, in turn, may impose constraints on daily behavioral activities, including song (Slabbekoorn and Smith 2002, this study). If, as suggested, dawn song indicates a phenotypic measure of reproductive fitness upon which female preference is based, vertical habitat specialization may have given way to temporal divergence in fitness related characters, such as an earlier dawn song, providing a potential substrate for assortative mating. 
Selection or Adaptation?- It is not yet clear whether birds have adapted to higher foraging strata in order to sing earlier, which implies some sort of benefit (i.e. broadcast coverage). However foraging strata is likely a more plastic trait than say, eye size.

Nevertheless, theoretical models have shown that even when assortative mating cannot alone split a population, quantitative traits associated with reproductive behaviors may prevent the merger of species after secondary contact (Kondrshov and Shpak 1998). Perhaps more plausible then, is a scenario in which populations were separated by, for example, vicariant events and then later reunited (secondary contact). The dynamic nature of major river systems in Amazonia (and likely other parts of the tropics) has been proposed as an important vicariant event explaining species richness in tropical birds (Remsen and Parker 1983), and also introduces important disruptions in ambient light patterns. A light-induced behavioral change in dawn singing during a separation phase may have facilitated further isolation of reproductive activities once two populations were reunited.

Female audience.- These hypothetical scenarios could be further explored by a better understanding of female behavior during the dawn chorus, which is at present poorly-known (Gorrison and Eens 2004), but nonetheless important (Mace 1986, 1987). In species where little sexual dimorphism occurs, one might expect females to operate under similar ecomorphological constraints as males, and thus may be more likely to listen attentively during the time block in which conspecific males are most vocal. For example, if males cease the dawn chorus when foraging becomes profitable due to morphological and habitat characteristics, females may also cease their assessment of male signaling at this time in order to forage. Male Great Tits (Parus major) cease dawn 
song when their mates emerge from the cavities to forage (Kacelnik and Krebs 1982, Gorrison and Eens 2004). Similarly, if males do not advertise earlier because a lack of visual acuity increases predation risk, then females operating under similar eye-size and ambient light constraints may not be able to interpret the context in which dawn song is given - or it may be too perilous to take action. That many passerine birds seem to become completely inactive beneath certain light levels (A. Sillman, pers comm.), combined with the light-mediated sequence to dawn song (Allard 1930, Leopold and Eynon 1961, Thomas et al. 2002, this study) further supports the argument that females may be likely to tune into the dawn chorus, especially during the peak in conspecific male output. Studies of captive birds may allow for assessment of female activity during the dawn chorus, because light intensity and aural stimuli can both be experimentally controlled.

Visual capacity.- Results provide additional support for the hypothesis that visual capability affects the timing of dawn song. Although eye size (relative to body size) could not alone predict the start of dawn song, when foraging height was controlled for statistically, evolutionary increases in eye size were correlated with singing earlier. The most likely explanation for this is that the ca. 10-fold decrease of light in the understory of tropical forests (Englebrecht and Herz 2001, pers. observ.) masks the effects of eye size and may mitigate against a straightforward relationship between eye size and time of dawn song found in the temperate. That light attenuates more in tropical forests than temperate forests, likely also contributed to the novel results. As expected, the strongest models found were those including both foraging height and eye size providing strong support for the hypothesis that visual capability determines the scheduling of the onset to dawn song in bird communities. 
Non-passerines were nearly as predictable as passerines regarding singing schedules, yet the biological causes of this variation may be remarkably different for the two groups. Phylogeny at the order and family level likely confounded potential effects of eye size and or foraging height on singing schedules of non-passerines, which was not as likely in the well resolved Passeriform order. Even within the passerines, suborder, tribe and family appeared to have partially confounded the relationship between foraging height and first song (see Fig. 6). This suggests that deeply-conserved traits within closely-related taxonomic groups influence the slope and intercept of the regression line. Most non-passerines families had only one or two representative species in this study, thus regression analysis at this level was not possible. Nevertheless, higher $r$-square values for groups of closely-related passerines (see Figure 6) may be the result of family level constraints associated with foraging behavior (i.e., prey type, capture mode) and or allometric constraints on eye size and body size. A better understanding of the function of song in non-passerine branches as it relates to particulars of diet and gregariousness may also eventually help interpret results reported here.

While no formal test was conducted, the pattern of canopy birds singing earlier seemed to be less valid as more primitive branches of birds were considered. For example, tinamous belong to the oldest extant lineage of birds, and provided an exception to nearly every prediction made in this study. They are terrestrial, small-eyed and were often the earliest to vocalize. Leopold and Eynon (1961) suggested that differences in spectral sensitivities of photoreceptor cells in the retina might help explain the differential start to dawn song. Tinamou retinas are thought to have a preponderance of rod cells, a visual system very different from most passerines (Sillman et al. 1981). This type of 
retina may provide tinamous with unusually acute scotopic vision, and perhaps explain why tinamous often sing in complete darkness (Sick 1993, Davies 2002).

Repeatability in the Tropics.- Time and light levels associated with first song were highly repeatable traits for a large assemblage of neotropical forest birds spanning ten avian orders. In this study species explained considerably less variation (48-71\%) than accounted for in temperate studies (82-90\%, Thomas et al. 2002). Lower repeatability in the tropics may be attributable to the fact that home range size is considerably larger in tropical birds than that found in similar-sized birds in the temperate zone (Terborgh et al. 1990, Stutchbury and Morton 2001), thus roosting sites may not be as predictable from day to day in tropical birds. This may have affected my ability to record accurately first vocalization each day in each species.

On the other hand, results here are robust in that they are based on means pooled across six different assemblages of birds, while most studies have used a smaller number of assemblages or only reported results on a per site basis. This also suggests that despite potential changes in social interactions between neighbors across sites (see Stoddard 1996), foraging height was a strong predictor of first song and was statistically significant in five of six sites (results not shown).

Temperature stochasticity?- Body size and temperature have also been shown to affect the dawn chorus in birds (Hutchinson 2002, Thomas et al. 2002, Thomas and Cuthill 2002). These studies predict birds are more likely to starve if overnight temperatures deplete an individual's energy surplus at dawn, and that smaller birds are less energy efficient and thus more likely to be effected. This might indicate that smaller birds, if they are to have a dawn chorus, may sing earlier after unusually cool nights. 
Thomas et al. (2002) reported a positive relationship between body size and the time of dawn song. In this study body mass or overnight minimum temperature had no noticeable effect on singing schedules. The simplest explanation for this is that the predictably warm overnight temperatures inherent to the lowland tropics have little effect on caloric reserves of birds at dawn, or that birds can better predict overnight loss of body mass and thus accumulate sufficient reserves the previous day. My data indicate a range of only $3^{\circ} \mathrm{C}$ in overnight minimum temperatures during one month in the wet season. European Robins (Erythacus rubecula) lose ca. $1 \%$ body mass for every $1{ }^{\circ} \mathrm{C}$ drop in overnight temperature (Thomas and Cuthill 2002), thus at most, the typical tropical bird in this study may have lost less than a third as much body mass as their temperate counterparts. However, this likely overestimates actual loss in tropical birds, because temperature in the European study site never climbed above $13.2^{\circ} \mathrm{C}$ - and at the Ecuadorian study site it never fell below $21^{\circ} \mathrm{C}$. That metabolic rates are thought to be lower in tropical birds (Bryant et al. 1984), would further argue for a lack of an effect due to temperature.

Elevation did not affect the timing of dawn song, perhaps due to the small altitudinal range of sites (e.g. $300 \mathrm{~m}$ ). A few select species did show an effect, but lack of replication did not allow for elaboration on this. It also cannot be discounted that lower temperatures, greater humidity and changing vegetation and species' ensembles (Terborgh 1977), including predators, may confound behavioral responses at higher elevations. Future studies should check this relationship over a larger altitudinal gradient using elevation replicates. The Rufous-colored Sparrow (Zonotrichia capensis) comes to 
mind as a good model because populations occur across huge elevation gradients in South America (Ridgely and Tudor 1989).

Conservation implications.- Neotropical forests are among the most highly threatened terrestrial habitats on earth (Gentry 1990) and provide important clues for understanding numerous aspects of behavioral ecology and evolution in birds (Kroodsma et al. 1996, Stutchbury and Morton 2001). Forest fragmentation is one of the greatest proximate threats to the health and stability of forest communities, although the mechanisms that lead to species' extirpation are still poorly understood. It is clear that numerous biophysical factors change with forest fragmentation, and that these likely set in motion a series of long-term changes in avian community composition (Stouffer and Bierregaard 1995). Perhaps the most immediate and irreversible of these changes is in the quantity and quality of forest light. Results here suggest that reproductive and territorial behaviors of birds are highly sensitive to, and may have co-evolved with changes in ambient light levels as they pertain to different microhabitats. Thus, even with selective logging of valuable timber species, important changes in light regimes may produce unknown effects on light-mediated reproductive and territorial activities of birds, as well as the foraging efficiency of their predators (Endler and Théry 1996). Data for this hypothesis could be gathered by comparing singing schedules in pristine forest versus altered forested habitats. In doing so, one would need to take into account time since fragmentation. Light probably functions as a zeitgeber and thus birds may become entrained to new light regimes created by forest alterations, and species assemblages eventually go through important changes as a result. 
In lieu of the above scenario, considerable efforts are underway to determine long-term changes in tropical forest communities as large expanses of habitat become further fragmented. Birds, owing to their diversity and relative ease of identification, are favorites of monitoring programs throughout the tropics and the temperate zone. Within these programs, aural surveys at dawn figure prominently in the researchers' tool-box of techniques, especially in the tropics (Terborgh et al. 1990, Parker 1991, Blake 1992, Haselmayer and Quinn 2000). Dawn is also convenient because it usually includes the diel peak of vocal activity of many diurnal and nocturnal birds. While shortcomings in aural surveys have been identified (Waide and Narins 1988, Schieck 1997, Haselmayer and Quinn 2000), studies conducted at dawn (i.e., circular point counts) may also need to take into account the predictable sequence of dawn song demonstrated in this and previous studies, in order to avoid spatial and temporal biases with respect to quantifying species' presence and abundance.

Summary:- As predicted by Leopold and Eynon (1961), birds in darker environments sang later and at higher light intensities than those associated with brighter habitats. Lack of a straightforward effect of eye size on singing routines does not refute results of previous studies, but may suggest caution be used with their broader geographic applications. Likewise, foraging height may not be a universal predictor of the onset of the dawn chorus if communities of birds have broader, more overlapping and unpredictable foraging, nesting or singing heights. For example, I see no reason why the temporal sequence in grassland bird communities, or species associated with forest-edge should be effected by foraging height - microhabitat light differences in these case are likely small. On the other hand, some of the earliest observations of the sequence to 
dawn song (e.g. Taylor 1929) suggest that passerines that sing in bright habitats

(swallows, thrushes, flycatchers) may lead the dawn chorus in the temperate zone as well. That relative eye-size is also rather large in these species (Ritland 1982), suggests that eye size and foraging height may be confounded in some bird communities.

Non-passerines, although highly predictable, provided important exceptions to most hypotheses tested and are clearly worthy of further study. Results corroborate past studies providing evidence that the availability of light affects the scheduling of the dawn chorus, but that proximate causes of singing routines in tropical birds may differ in two ways: 1) ecological constraints that surround the high degree of habitat specialization may mask the effects of visual capability on time of dawn song; and 2) lack of an effect of body size and or temperature may reflect a reduced risk of overnight starvation, due to predictably warm temperatures that characterize the lowland tropics.

Ultimate causes of the temporal sequence, and thus an important period for acoustic signaling in many species, are likely linked to the diversity of ecological attributes, social systems and life history strategies represented in a given community. Because this diversity culminates in tropics, studies of the tropical dawn chorus may offer clues to understanding a nearly universal, poorly understood, nonetheless spectacular display of avian vocal behavior. 


\section{LITERATURE CITED}

Allard, H. A. 1930. The first morning song of some birds of Washington, D.C.; its relation to light. American Naturalist 64:436-469.

Allen, F. H. 1913. More notes on the morning awakening. Auk 30:229-235.

Armstrong, E. A. 1963. A study of bird song. Oxford University Press.

Bell, H. L. 1982. A bird community of New Guinean lowland rainforest. 3 Vertical distribution of the avifauna. Emu 82:143-162.

Bennett, A. T. D., I. C. Cuthill and K. J. Norris. 1994. Sexual selection and the mismeasure of color. American Naturalist 144:848-860.

Berg, K. S. 2001. Notes on the natural history of the Pale-mandibled Araçari. Journal Field Ornithology 72:258-266.

Blake, J. G. 1992. Temporal variation in point counts of birds in a lowland wet forest in Costa Rica. Condor 94:265-275.

Bryant, D. M., C. J. Hails and P. Tatner. Reproductive energetics of two tropical bird species. Auk 101:25-37.

Campbell, G. S. and J. M. Norman. 1998. An introduction to environmental biophysics. $2^{\text {nd }}$ Ed. Springer-Verlag, NY.

Chesser, R. T. 2004. Molecular systematics of New World suboscine birds. In-press, Molecular Phylogenetics and Evolution.

Coopmans, P., J. V. Moore, N. Krabbe, O. Jahn, K. S. Berg, M. Lysinger, L. Navarrete and R. S. Ridgely. 2004. The birds of southwest Ecuador. (Audio publication) J.V. Moore Nature Recordings, San Jose, CA.

Crandall, K. A. 1997. Rhodopsin evolution in the dark. Nature 387:667-668.

Davies, S. J. J. F. 2002. Ratites and tinamous. Oxford University Press, New York.

Endler, J. A. 1992. Signals, signal conditions and the direction of evolution. American Naturalist 139:125-153.

1993. The color of light in forests and its implications. Ecological Monographs 63:1-27. 
and M. Théry. 1996. Interacting effects of lek placement, display behavior, ambient light, and color patterns in three neotropical forest-dwelling birds. American Naturalist 148:421-452.

Engelbrecht, B. M. and H. M. Herz. 2001. Evaluation of different methods to estimate understory light conditions in tropical forests. Journal of Tropical Ecology 17:207-224.

Garvin, M. C. and J. V. Remsen. 1997. An alternative hypothesis for heavier parasite loads of brightly colored birds: exposure at the nest. Auk 114:179-191.

Gentry, A. H. 1990. Four neotropical forests (ed.), Yale University Press, New Haven.

Gomez, D. and M. Théry. 2004. Influence of ambient light on the evolution of colour signals: comparative analysis of a Neotropical rainforest bird community. Ecology Letters 7: 279-284.

Gorrison, L. and M. Eens. 2004. Interactive communication between male and female great tits (Parus major) during the dawn chorus. Auk 121:184-191.

Haselmayer, J. and J. S. Quinn. 2000. A comparison of point counts and sound recording as bird survey methods in Amazonian southeastern Peru. Condor 102:887-893.

Hau, M., M. Wikelski and J. C. Wingfield. 1998. A neotropical forest bird can measure the slight changes in tropical photoperiod. Proceedings Royal Society London B. 265:89-95.

Henwood, K. and A. Fabrick. 1979. A quantitative analysis of the dawn chorus: temporal selection for communicatory optimization. American Naturalist 114:260-274.

Hutchinson, J. M. C. 2002. Two explanations of the dawn chorus compared: how monotonically changing light levels favour a short break from singing. Animal Behaviour 64:527-539.

Irestedt, M., J. Fjeldså, U. S. Johansson and P. G. P. Ericson. 2002. Systematic relationships and biogeography of the tracheophone suboscines (Aves: Passeriformes). Molecular Phylogenetics Evolution 23:499-512.

INAMHI. 1996. Anuario meterológico 1994. Insituto nacional de meterología e hidrología. Quito, Ecuador.

Jahn, O., J. V. Moore, P. M. Valenzuela, N. Krabbe, P. Coopmans, M. Lysinger and R. S. Ridgely. 2002. The birds of northwest Ecuador Vol. II: the lowlands and lower foothills. (Audio publication). J.V. Moore Nature Recordings, San Jose, CA. 
Kacelnick, A. 1979. The foraging efficiency of great tits (Parus major L.) in relation to light intensity. Animal Behaviour 27:237-241.

Kacelnick, A. and J. R. Krebs. 1982. The dawn chorus in the great tit (Parus major): proximate and ultimate causes. Behaviour 83:287-309.

Kondrashov, A. S. and M. Shpak. 1998. On the origin of species by means of assortative mating. Proceedings Royal Society London, B. 265:2273-2278.

Krams, I. 2001. Communication in crested tits and the risk of predation. Animal Behaviour 61:1065-1068.

Kroodsma, D. E., J. M. E. Vielliard and F. G. Stiles. 1996. Study of bird sounds in the Neotropics: urgency and opportunity. In Ecology and evolution of acoustic communication in birds (Eds) D. E. Kroodsma and E. H. Miller. Cornell, Ithaca, NY.

Lee, D. W. 1987. The spectral distribution of radiation in two neotropical rainforests. Biotropica 19:161-166.

Lessells, C. M. and P. T. Boag. 1987. Unrepeatable repeatabilities: a common mistake. Auk 104:116-121.

Leopold, A. and A. Eynon. 1961. Avian daybreak and evening song in relation to time and light intensity. Condor 63:269-293.

MacArthur, R. H. and E. O. Wilson. 1967. Theory of island biogeography. Monographs Population Biology: 1, Princeton University Press, New Jersey.

Mace, R. 1986. Importance of female behavior in the dawn chorus. Animal Behaviour 34:623-635

1987. The dawn chorus in the great tit Parus major is directly related to female fertility. Nature 330:745-746.

Marchant, S. 1959. The breeding season in S.W. Ecuador. Ibis 101: 137-152.

Marchetti, K. 1993. Dark habitats and bright birds illustrate the role of environment in species divergence. Nature 362:149-152.

Marra, P. P. and J. V. Remsen, Jr. 1997. Insights into the maintenance of high species diversity in the Neotropics: habitat selection and foraging behavior in understory birds of tropical and temperate forests. Ornithological Monographs 48:445-483. 
Morton. E. S. 1975. Ecological sources of selection on avian sounds. American Naturalist 108:17-34.

--19-1.-.- 1996. A comparison of vocal behavior among tropical and temperate passerine birds. in Ecology and evolution of acoustic communication in birds. $(E d s)$ D. E. Kroodsma and E. H. Miller. Cornell. Ithaca.

Munn, C. A. and J. W. Terborgh. 1979. Multi-species territoriality in neotropical foraging flocks. Condor 81:338-347.

Otter, K., B. Chruszcz and L. Ratcliffe. 1997. Honest advertisement and song output during the dawn chorus of black-capped chickadees. Behav. Ecol. 8:167-173.

Parker, T. A. III. 1991. On the use of tape recorders in avifaunal surveys. Auk 108:443444.

Pearson, D. L. 1971. Vertical stratification of birds in a tropical dry forest. Condor 73:46-55.

1975. The relation of foliage complexity to ecological diversity of three Amazonian bird communities. Condor 77:453-466.

1977. A pantropical comparison of bird community structure on six lowland forest sites. Condor 79:232-244.

Pianka, E. R. 2000. Evolutionary ecology. $6^{\text {th }}$ Ed. University of Texas Press, Austin.

Purvis, A. and A. Rambaut. 1995. Comparative analysis by independent contrasts (CAIC): an Apple Macintosh application for analyzing comparative data. Computer Applied Biosciences 11:247-251.

Remsen, J. V., Jr. 1994. Use and misuse of birds lists in community ecology and conservation. Auk 111:225-227.

and T. A. Parker, III. 1983. Contribution of river-created habitats to bird species richness in Amazonia. Biotropica 15:223-231.

and S. K. Robinson. 1990. A classification scheme for foraging behavior of birds in terrestrial habitats. In Avian foraging: theory, methods and applications. (Eds) M.M. Morrison, C.J. Ralph, J.Verner and J.R. Jehl, Jr. Studies in Avian Biology 13:144-160.

Richards, D. G. and R. H. Wiley. 1980. Reverberations and amplitude fluctuations in the propagation of sound in a forest: implications for animal communication. American Naturalist 115:381-399. 
Ridgely, R. S. and G. Tudor. 1989. The birds of South America, Volume I. University of Texas Press, Austin. Ithaca, NY.

Ritland, S. 1982. Allometry of the vertebrate eye. University of Chicago. Ph.D. Dissertation.

Russo, S. E., S. K. Robinson, J. Terborgh. 2003. Size-abundance relationships in an Amazonian bird community: implications for the energetic equivalence rule. American Naturalist 161:267-283.

Schieck, J. 1997. Biased detection of bird vocalizations affects comparisons of bird abundance among forested habitats. Condor 99:179-190.

Searcy, W. A. and M. Andersson. 1986. Sexual selection and the evolution of song. Annual Review Ecology and Systematics 17:507-33.

and K. Yasukawa. 1996. Song and female choice. in Ecology and evolution of acoustic communication in birds. (Eds) D. E. Kroodsma and E. H. Miller. Cornell University Press, Ithaca, NY.

Sibley, C. G. and J. E. Ahlquist. 1990. Phylogeny and classification of birds. Yale University Press, New Haven.

Sick, H. 1993. Birds in Brazil. Princeton University Press, New Jersey.

Sillman, A. J., D. A. Bolnick, L. W. Haynes, A. E. Walter, and E. R. Loew. 1981. Microspectrophotometry of the photoreceptors of palaeognathous birds - the emu and the tinamou. Journal Comparative Physiology 144:271-276.

Slabbekoorn, H. and T. B. Smith. 2002. Habitat-dependent song divergence in the little greenbul: an analysis of environmental selection pressures on acoustic signals. Evolution 56:1849-1858.

Staicer, C. A., D. A. Spector and A. G. Horn. 1996. The dawn chorus and other diel patterns in acoustic signaling. in Ecology and evolution of acoustic communication in birds. (Eds) D. E. Kroodsma and E. H. Miller. Cornell. Ithaca.

Stoddard, P. K. 1996. Vocal recognition of neighbors by territorial passerines. in Ecology and evolution of acoustic communication in birds. $(E d s) \mathrm{D}$. E. Kroodsma and E. H. Miller. Cornell. Ithaca. 
Stouffer, P. C. and R. O. Bierregaard Jr. 1995. Use of Amazonian forest-fragments by understory insectivorous birds. Ecology 76:2429-2445.

Stutchbury, B. J. and E. S. Morton. 2001. Behavioral ecology of tropical birds. Academic Press.

Terborgh, J. 1977. Bird species diversity on an Andean elevation gradient. Ecology 58:1007-1019.

-.-.-..., S. K. Robinson, T. A. Parker 11I, C. A. Munn and N. Pierpont. 1990. Structure and organization of an Amazonian forest bird community. Ecological Monographs. 60:213-238.

Thomas, R. J. 1999. Two tests of a stochastic dynamic programming model of daily singing routines in birds. Animal Behaviour 57:277-284.

, and I. C. Cuthill. 2002. Body mass regulation and the daily singing routines of European robins. Animal Behaviour 63:285-295.

T. Szekely, 1.C. Cuthill, D.G.C. Harper, S.E. Newson, T.D. Frayling and P.D. Wallis. 2002. Eye size in birds and the timing of song at dawn. Proceedings Royal Society London B. 269: 831-837.

Taylor, W. P. 1929. Order of awakening of some Arizona birds. Auk XLVI:399.

Walther, B. A. 2002. Grounded ground birds and surfing canopy birds: variation of foraging stratum breadth observed in neotropical forest birds and tested with simulation models using boundary constraints. Auk 119:658-675.

D. H. Clayton and R. D. Gregory. 1999. Showiness of neotropical birds in relation to ectoparasite abundance and foraging stratum. Oikos 87:157-165.

Waide, R. B. and P. M. Narins. 1988. Tropical forest bird counts and the effect of sound attenuation. Auk 105:296-302.

Willis, E. O. 1972. The behavior of Plain-brown Woodcreepers, Dendrocincla futiginosa. Wilson Bulletin. 84:377-420.

and Y. Oniki. 1978. Birds and army ants. Annual Review Ecology Systematics 9:243-263.

Wright, H. W. 1913. Morning awakening and even-song. Auk 30:512-537

Zar, J. H. 1999. Biostatistical analysis. $4^{\text {th }}$ ed. Pearson education Inc., India. 
APPENDIX I. List of bird species occurring in the Tito Santos Biological Station $\left(0^{\circ} 11^{\prime}, 81^{\circ} 00 \mathrm{~W}\right)$ and adjacent areas of northwest Manabi Province, Ecuador, with species participation in the dawn chorus. The list was compiled based on personal observations made between 8 May - 10 June 2002 and 23 Jan - 3 Mar 2003 (ca. 500 person-hours). Participation consisted of vocalizations registered during 100-minute continuous, omni-directional recordings, synchronized with local twilight on 25 different mornings between 27 January and 27 February 2003. Frequency of singing observations are given for each recording locality as indicated by its elevation $(\mathrm{m})$. Species that were only observed outside the station and ranch, but within a $50 \mathrm{~km}$ radius are given a "*". The " $R$ " column indicates type of evidence (taped or visual) for the occurrence of a particular species and "?" if more information is needed to confirm presence. The "P" column indicates species included in analysis of phylogenetic independent contrasts of dawn singing schedules. Inclusion was based on the delineation of the core forest avifauna and repeatability of first song. The "H" column gives main habitat type as follows: $\mathrm{F}=$ forest; $\mathrm{SF}=$ secondary forest; $\mathrm{A}=$ aquatic; $\mathrm{D}=$ disturbed areas; and $\mathrm{M}=$ Migrant. Bold-faced rows indicate evidence of breeding was found. Taxonomy and nomenclature follow Ridgely and Greenfield (2001).

\begin{tabular}{|c|c|c|c|c|c|c|c|c|c|c|}
\hline \multirow{2}{*}{\multicolumn{2}{|c|}{$\begin{array}{l}\text { ORDER } \\
\text { FAMILY and Species }\end{array}$}} & \multicolumn{8}{|c|}{ SITES (m) } & \multirow[b]{2}{*}{$\mathbf{P}$} \\
\hline & & R 5 & 0100 & 150 & 220 & 280 & 350 & $N$ & $\mathrm{H}$ & \\
\hline \multicolumn{11}{|c|}{ TINAMIFORMES } \\
\hline \multicolumn{11}{|c|}{ TINAMIDAE } \\
\hline 1 & Tinamus major & $T$ & 1 & 3 & 4 & 2 & 3 & 16 & $\mathrm{~F}$ & $\mathrm{P}$ \\
\hline 2 & Crypturellus soui & $\mathrm{T}$ & 5 & 5 & 5 & 3 & 3 & 25 & $\mathrm{~F}$ & $\mathrm{P}$ \\
\hline 3 & C. transfasciatus & $T$. & 5 & 5 & 5 & 3 & 2 & 24 & $\mathrm{~F}$ & \\
\hline \multicolumn{11}{|c|}{ PODICIPEDIFORMES } \\
\hline \multicolumn{10}{|c|}{ PODICIPEDIDAE } & \\
\hline 4 & Podilymbus podiceps & V & & & & & & 0 & A & \\
\hline \multicolumn{11}{|c|}{ PELECANIFORMES } \\
\hline \multicolumn{11}{|c|}{ FREGATIDAE } \\
\hline 5 & $\begin{array}{r}\text { Fregata magnificens } \\
\text { PHALACROCORACIDAE }\end{array}$ & V & & & & & & 0 & A & \\
\hline \multirow[t]{2}{*}{6} & $\begin{array}{l}\text { * Phalacrocorax brasilianus } \\
\text { PELECANIDAE }\end{array}$ & V & & & & & & 0 & A & \\
\hline & \multicolumn{10}{|c|}{ ANSERIFORMES } \\
\hline \multicolumn{11}{|c|}{ ANSERIDAE } \\
\hline 8 & * Dendrocygna autumnalis & V & & & & & & 0 & A & \\
\hline \multicolumn{11}{|c|}{ CICONIIFORMES } \\
\hline \multicolumn{10}{|c|}{ ARDEIDAE } & \\
\hline 9 & Ardea cocoi & v & & & & & & 0 & A & \\
\hline 10 & A. alba & V & & & & & & 0 & A & \\
\hline 11 & Egretta thula & V & & & & & & 0 & A & \\
\hline 12 & * E. tricolor & V & & & & & & 0 & A & \\
\hline
\end{tabular}


ORDER

FAMILY and Species

\begin{tabular}{ll}
\hline 13 & Bubulcus ibis \\
14 & Butorides striatus \\
15 & $* \quad$ Nycticorax nycticorax \\
& FALCONIFORMES \\
& CATHARTIDAE \\
16 & Coragyps atratus \\
17 & Cathartes aura \\
& ACCIPITRIDAE \\
18 & * Pandion haliaetus \\
19 & Chondrohierax uncinatus \\
20 & Elanoides forficatus \\
21 & Elanus leucurus \\
22 & Rostrhamus sociabilis \\
23 & Ictinia plumbea \\
24 & Leocopternis occidentalis \\
25 & Buteogallus meriodionalis \\
26 & B. urubitinga \\
27 & Parabuteo unicinctus \\
28 & Buteo nitidus \\
29 & B. magnirostris \\
30 & B. albonatus \\
& FAI
\end{tabular}

FALCONIDAE
Micrastur ruficollis

M. semitorquatus

Cathartes aura

ACCIPITRIDAE

* Pandion haliaetus

Chondrohierax uncinatus

Elanoides forficatus

Elanus leucurus

Rostrhamus sociabilis

Ictinia plumbea

Leocopternis occidentalis

* Buteogallus meriodionalis

$$
\text { B. urubitinga }
$$

Parabuteo unicinctus

Buteo nitidus

B. magnirostris

B. albonatus
Herpetotheres cachinnans

\section{SITES $(\mathrm{m})$}

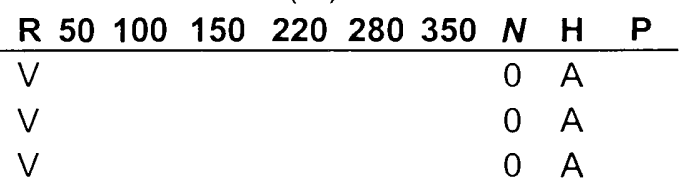

T

V

V

$T$

V

V

V

$\mathrm{V}$

T

$\checkmark$

V

V

$\mathrm{T}$

T

V
0 F

$0 \mathrm{~F}$

0 A

$0 \mathrm{~F}$

$0 \mathrm{~F}$

0 D

$0 \mathrm{SF}$

$0 \mathrm{~F}$

$0 \mathrm{~F}$

$0 \mathrm{SF}$

0 SF

0 SF

0 SF

$2 \mathrm{SF}$

$0 \mathrm{~F}$

$$
\begin{array}{cccccc}
2 & 2 & 3 & 10 & F & \\
2 & 1 & 1 & 8 & F & P \\
& 2 & 2 & 4 & F & P \\
& & & & & \\
& & & &
\end{array}
$$

v

$0 \mathrm{~A}$

$0 \mathrm{~F}$

$0 \mathrm{~F}$

0 D

O SF

$0 \mathrm{~F}$

$0 \mathrm{~F}$

$0 \mathrm{SF}$

$0 \mathrm{SF}$

$0 \mathrm{SF}$

0 SF

$2 \mathrm{SF}$

$0 \mathrm{~F}$ 
APPENDIX. Continued.

ORDER

FAMILY and Species

FALCONIDAE

31

32

33

\section{GALLIFORMES}

CRACIDAE

34

Ortalis erythroptera ODONTOPHORIDAE

35 Odontophorus erythrops

\section{GRUIFORMES}

RALLIDAE

36 * Aramides axillaris

$37 \quad$ A. wolfi

38 * Porphyrula martinica

\section{CHARADRIIFORMES}

JACANIDAE

39

* Jacana jacana

SCOLOPACIDAE

$40 \quad$ Actitis macularia

41 * Numenius phaeopus

LARIDAE

42 * Himantopus mexicanus

43 * Laurus atricilla

44 * Sterna anaethetus

45

\section{COLUMBIFORMES}

COLUMBIDAE

46

47

Columba livia

48

C. speciosa

49

C. cayennensis

50

C. subvinacea

51

52

C. goodsoni

Zenaida auriculata

Columbina buckleyi

53
SITES $(\mathrm{m})$

$\begin{array}{llllllllll}\text { R } & 50 & 100 & 150 & 220 & 280 & 350 & N & H & P\end{array}$

$\begin{array}{lllllllll}\mathrm{T} & 2 & 1 & 2 & 2 & 3 & 10 & \mathrm{~F} & \\ \mathrm{~T} & 1 & 3 & 2 & 1 & 1 & 8 & \mathrm{~F} & \mathrm{P} \\ \mathrm{T} & & & & 2 & 2 & 4 & \mathrm{~F} & \mathrm{P}\end{array}$

$\begin{array}{llllllllll}\mathrm{T} & 1 & 2 & 3 & 5 & 3 & 2 & 16 & \mathrm{~F} & \mathrm{P}\end{array}$

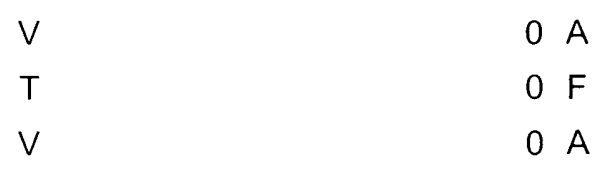

V

$0 \mathrm{~A}$

V

$0 \mathrm{~A}$

V

$0 \mathrm{~A}$

V

$0 \mathrm{~A}$

V

$0 \mathrm{~A}$

V

$0 \mathrm{~A}$

V

$0 \mathrm{~A}$

\begin{tabular}{|c|c|c|c|c|c|c|c|}
\hline V & & & & & & & $D$ \\
\hline $\mathrm{T}$ & 1 & 1 & & 1 & & & SF \\
\hline$T$ & & & & & & & SF \\
\hline $\mathrm{T}$ & 2 & 2 & 1 & 2 & 1 & 311 & $F$ \\
\hline$?$ & & & & & & & $F$ \\
\hline $\mathrm{T}$ & & & & & & & $D$ \\
\hline $\mathrm{T}$ & & & & & & & SF \\
\hline V & & & & & & & $D$ \\
\hline
\end{tabular}


APPENDIX. Continued.

ORDER

SITES $(\mathrm{m})$

\begin{tabular}{lllllllllllllll} 
& FAMILY and Species & R & 50 & 100 & 150 & $\mathbf{2 2 0}$ & $\mathbf{2 8 0}$ & $\mathbf{3 5 0}$ & $\mathbf{N}$ & $\mathbf{H}$ & $\mathbf{P}$ \\
\hline 54 & Claravis pretiosa & $\mathrm{T}$ & 4 & 5 & 4 & 4 & 2 & 3 & 22 & $\mathrm{~F}$ & $\mathrm{P}$ \\
55 & Leptotila verreauxi & $\mathrm{T}$ & 1 & 3 & 5 & 3 & 1 & & 13 & $\mathrm{SF}$ & \\
56 & L. pallida & $\mathrm{T}$ & 5 & 4 & 5 & 5 & 3 & 3 & 25 & $\mathrm{~F}$ & $\mathrm{P}$ \\
57 & L. ochraceiventris & $\mathrm{T}$ & & & 4 & 4 & & & 8 & $\mathrm{~F}$ & \\
58 & Geotrygon montana & $\mathrm{T}$ & 4 & 3 & 2 & & 1 & & 10 & $\mathrm{~F}$ & $\mathrm{P}$
\end{tabular}

PSITTACIFORMES

PSITTACIDAE

59

60

61 Brotogeris pyrrhopterus

62 Touit dilectissima

63 Pionus menstruus

$64 \quad P$. chalcopterus

CUCULIFORMES

CUCULIDAE

65

Coccyzus lansbergi

66

C. euleri

67

Piaya cayana

68

Chrotophaga sulcirostris

69

C. ani

70

Tapera naevia

STRIGIFORMES

TYTIONIDAE

71

Tyto alba

STRIGIDAE

72

Otus centralis

73

Glaucidium peruanum

$74 \quad$ Pulsatrix perspicillata

75 Strix nigrolineata

76 S. virgata

77 Asio clamator

CAPRIMULGIFORMES

CAPRIMULGIDAE

78

Nyctibius griseus

79

Nyctidromus albicollis

\begin{tabular}{|c|c|c|c|c|c|c|}
\hline $\mathbf{T}$ & 4 & 5 & 5 & 5 & 3 & $325 \mathrm{~F}$ \\
\hline V & & & & & & $0 \mathrm{SF}$ \\
\hline $\mathrm{T}$ & & & & & & $0 \mathrm{SF}$ \\
\hline $\mathrm{T}$ & & & & & & $0 \mathrm{~F}$ \\
\hline$T$ & 2 & 3 & 4 & 4 & 3 & $218 \mathrm{~F}$ \\
\hline T & 2 & 3 & 3 & 4 & 3 & $217 \mathrm{~F}$ \\
\hline
\end{tabular}

$\mathrm{T}$

O SF

T

OF,M

$\mathrm{T}$

T

$15 \mathrm{~F} \quad \mathrm{P}$

$0 \mathrm{SF}$

$0 \mathrm{SF}$

$0 \mathrm{SF}$
A

$\mathrm{T}$

$\mathrm{T}$

T

$\mathrm{T}$

T

T

T

T
$0 \mathrm{D}$

$0 \mathrm{~F}$

$0 \mathrm{SF}$

$0 \mathrm{~F}$

$0 \mathrm{~F}$

$0 \mathrm{~F}$

$0 \mathrm{SF}$ 
APPENDIX. Continued.

ORDER

SITES $(\mathrm{m})$

FAMILY and Species

R 50100

Caprimulgus anthonyi

$T$

0 D

APODIFORMES

APODIDAE

81

Streptoprocne zonaris

$\checkmark$

$0 \mathrm{~F}$

82

Panyptila cayennensis

V

$0 \mathrm{~F}$

TROCHILIDAE

83

Phaethornis baroni

$84 \quad$ Anthracothorax nigricollis$$
T
$$

T

85 Popelairia conversii

V

$T$

T

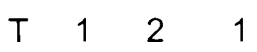

$\mathrm{T}$

V

V

V

$14 \mathrm{~F}$

$0 \mathrm{~F}$

$0 \mathrm{SF}$

$0 \mathrm{~F}$

Amazilia tzacatı

88

A. amazilia

89

A. amabilis

$90 \quad$ Heliothryx

91 Heliomaster longirostris

92 * Myrmia micrura

TROGONIFORMES

TROGONIDAE

$\begin{array}{ll}93 & \text { Trogon mesurus } \\ 94 & \text { T. chionurus } \\ 95 & \text { T. caligatus }\end{array}$

CORACIFORMES

ALCEDINIDAE

$96 \quad$ Megaceryle torquata

97 Chlorocerele americana

MOMOTIDAE

98

Momotus momota

PICIFORMES

GALBULIDAE

99

Galbula ruficauda

BUCCONIDAE

100

Notharcus macrorhynchos

$\mathrm{T}$

$0 \mathrm{~A}$

T

$0 \mathrm{~A}$

$\begin{array}{cccccccccc}\mathbf{T} & \mathbf{4} & \mathbf{4} & \mathbf{5} & \mathbf{5} & \mathbf{3} & \mathbf{3} & \mathbf{2 4} & \mathbf{F} & \mathbf{P} \\ \mathrm{T} & 1 & 1 & 2 & 1 & 2 & 1 & 8 & \mathrm{SF} & \\ \mathrm{T} & & & 2 & 3 & & 1 & 6 & \mathrm{~F} & \end{array}$

101

Nystalus radiatus

102

Malacoptila panamensis

$\begin{array}{lllll} & 5 & 5 & 5 & 5\end{array}$

$222 \mathrm{~F} P$

$4 F \quad P$

$0 \mathrm{~F}$

$0 \mathrm{~F}$

$0 \mathrm{~F}$

O SF 
APPENDIX. Continued.

ORDER

SITES $(m)$

FAMILY and Species

$\begin{array}{llllllllll}\text { R } & 50 & 100 & 150 & 220 & 280 & 350 & N & \text { H } & \text { P }\end{array}$

RAMPHASTIDAE

103

Pteroglossus erythropygius

104

Ramphastos brevis

105

R. swainsonii

$\begin{array}{lll}\mathrm{T} & & \\ \mathrm{T} & 1 & \\ \mathrm{~T} & 2 & 1\end{array}$

$\begin{array}{llllll}1 & 1 & 1 & 3 & \mathrm{~F} & \mathrm{P} \\ 2 & & & 3 & \mathrm{~F} & \\ 2 & & & 5 & \mathrm{~F} & \mathrm{P}\end{array}$

PICIDAE

106

107

Piculus rubiginosus

$T$

$T$

108

Melanerpes pucherani

109

Veniliornis kirkii

110

V. callonatus

$\mathrm{T}$

$\mathrm{T}$

T

Campephilus gayaquilensis

PASSERIFORMES

FURNARIIDAE

111

112

113

114

115

116

117

118

119

120

121

122

123

124

125

126

127

128

129

130

131
Furnarius cinnamomeus

Automolus ochralaemus

Xenops rutilans

$X$. minutus

Hyloctistes virgatus

Sclerurus guatemalensis

DENDROCOLAPTIDAE

Campylorhamphus trochilirostris

Dendrocincla fuliginosa

Sittasomus griseicapillus

Dendrocolaptes sanctithomae

Xiphorhynchus lachrymosus

$X$. erythropgyius

Lepidocolaptes souleyetii

THAMNOPHILIDAE

Cymbilaimus lineatus

Taraba major

* Sakesphorus bernardi

Thamnophilus atrinucha

Dysithamnus mentalis

Myrmotherula ignota

M. fulviventris

M. schisticolor

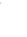

$0 \mathrm{SF}$

$0 \mathrm{SF}$

$12 \mathrm{~F} P$

$0 \mathrm{SF}$

$\begin{array}{lllll}1 & 1 & 2 & \mathrm{~F} & \mathrm{P}\end{array}$ 
APPENDIX. Continued.

\begin{tabular}{|c|c|c|c|c|c|c|c|c|c|c|c|c|}
\hline \multirow{2}{*}{\multicolumn{2}{|c|}{$\begin{array}{l}\text { ORDER } \\
\quad \text { FAMILY and Species }\end{array}$}} & \multicolumn{10}{|c|}{ SITES $(m)$} & \multirow{3}{*}{$\mathbf{P}$} \\
\hline & & \multirow{2}{*}{$\frac{\mathbf{R}}{\mathrm{T}}$} & \multicolumn{2}{|c|}{50100} & \multirow[t]{2}{*}{150} & \multirow{2}{*}{\multicolumn{2}{|c|}{220}} & \multicolumn{3}{|c|}{280350} & & \\
\hline 132 & Herpsilochmus rufimarginatus & & & & & & & 2 & 2 & & & \\
\hline 133 & Microrhopias quixensis & $\mathrm{T}$ & 2 & 3 & & 2 & 5 & 1 & 1 & 3 & $16 \mathrm{~F}, \mathrm{~N}$ & \\
\hline 134 & Cercomacra nigricans & $?$ & & & & & & & & & $0 \mathrm{~F}$ & \\
\hline 135 & Pyriglena leuconota & $T$ & 1 & 2 & & 5 & 4 & 1 & 1 & & $13 \mathrm{~F}$ & $\mathrm{P}$ \\
\hline 136 & Myrmeciza immaculata & $?$ & & & & & & & & & $0 \mathrm{~F}$ & \\
\hline 137 & M. exsul & $\mathrm{T}$ & 4 & 4 & & 3 & 4 & 3 & 3 & 3 & $21 \mathrm{~F}$ & $\mathrm{P}$ \\
\hline \multirow[t]{2}{*}{138} & Gymnopithys leucaspis & $\mathrm{T}$ & & 2 & & & & 1 & 1 & 1 & $4 \mathrm{~F}, \mathrm{~N}$ & \\
\hline & $R M I C A R I I D A E$ & & & & & & & & & & & \\
\hline 139 & Formicarius nigricapillus & $\mathrm{T}$ & 2 & & & 2 & 4 & 3 & 3 & 3 & $14 \mathrm{~F}$ & $\mathrm{P}$ \\
\hline \multirow[t]{2}{*}{140} & Grallaria guatimalensis & $\mathrm{T}$ & 1 & & & & & & & & $1 \mathrm{~F}$ & \\
\hline & INOCRYPTIDAE & & & & & & & & & & & \\
\hline \multirow[t]{2}{*}{141} & Melanopareia elegans & $\mathrm{T}$ & & & & & & & & & $0 \mathrm{SF}$ & \\
\hline & RANNIDAE & & & & & & & & & & & \\
\hline 142 & Phyllomyias griseiceps & $\mathrm{T}$ & & 1 & & & & & & 1 & $2 \mathrm{SF}$ & \\
\hline 143 & Ornithion brunneicapillum & $\mathrm{T}$ & 1 & & & & & & & 2 & $3 \mathrm{SF}$ & \\
\hline 144 & Camptostoma obsoletum & $\mathrm{T}$ & & 4 & & 3 & 1 & 3 & 3 & & $11 \mathrm{SF}$ & \\
\hline 145 & Tyrannulus elatus & $\mathrm{T}$ & & & & 2 & 2 & & & 1 & $5 \mathrm{SF}$ & \\
\hline 146 & Myiopagis subplacens & $\mathrm{T}$ & & & & & & & & & $0 \mathrm{SF}$ & \\
\hline 147 & M. viridicata & $\mathrm{T}$ & 1 & 3 & & 1 & & 1 & 1 & 2 & $8 \mathrm{SF}$ & \\
\hline 148 & Elaenia flavogaster & $\mathbf{T}$ & & & & 1 & & & & & $1 \mathrm{SF}$ & \\
\hline 149 & Euscarthmus meloryphus & $\mathrm{T}$ & & & & & & & & & $0 \mathrm{SF}$ & \\
\hline 150 & Mionectes oleagineus & V & & & & 1 & & & & & $1 \mathrm{~F}$ & \\
\hline 151 & Leptopogon superciliarus & $?$ & & & & & & & & & $0 \mathrm{~F}$ & \\
\hline 152 & Capsiempis flaveola & $T$ & & & & & & & & & $0 S F$ & \\
\hline 153 & Lophotriccus pileatus & $\mathrm{T}$ & 4 & 5 & & 5 & 5 & 3 & 3 & & $25 \mathrm{~F}$ & $P$ \\
\hline 154 & Todirostrum nigriceps & V & & & & & & & & & $0 \mathrm{SF}$ & \\
\hline 155 & $T$. cinereum & $\mathrm{T}$ & & & & & & & & & $0 \mathrm{SF}$ & \\
\hline 156 & Cnipodectes subbrunneus & $\mathrm{T}$ & 4 & 3 & & 1 & 4 & & & & $12 \mathrm{~F}$ & $\mathrm{P}$ \\
\hline 157 & Tolmomyias sulphurescens & $\mathbf{T}$ & & & & & & 1 & 1 & 1 & $2 S F$ & \\
\hline 158 & Platyrinchus mystaceus & V & & & & & & & & & $0 \mathrm{~F}$ & \\
\hline 159 & Onychorhynchus occidentalis & $\mathbf{T}$ & 1 & & & 2 & & & & & $3 \mathrm{~F}$ & $\mathbf{P}$ \\
\hline 160 & Myiobius atricaudus & V & & & & & & & & & $0 \mathrm{SF}$ & \\
\hline 161 & Myiophobus fasciatus & $\mathrm{T}$ & & & & & & & & 1 & $1 \mathrm{SF}$ & \\
\hline 162 & Contopus punensis & $\mathrm{T}$ & & & & & & & & & $0 \mathrm{SF}$ & \\
\hline 163 & C. cooperi & $\mathrm{T}$ & & & & & & & & & $0 \mathrm{M}$ & \\
\hline
\end{tabular}


APPENDIX. Continued.

ORDER

SITES $(m)$

FAMILY and Species

$\begin{array}{llllllllll}\text { R } 50 & 100 & 150 & 220 & 280 & 350 & \text { N } & \text { H } & \text { P }\end{array}$

164

165

166

167

168

169

170

171

172

173

174

175

176

177

178

179

180

181

182

183

184

185

186

187

188

188

189

190

191

192
Empidonax virescens

Lathrotriccus griseipectus

* Pyrocephalus rubinus

Fluvicola nengeta

Rhytipterna holerythra

Myiarchus tubeculifer

Megarynchus pitangua

Myiozetetes similis

M. cayanensis

Myiodynastes maculatus

M. bairdii

Legatus leucophaius

Tyrannus melancholicus

$T$. niveigularis

Platypsaris homochrous

Tityra semifasciata

$T$. inquisitor

PIPRIDAE

$$
\text { Manacus manacus }
$$

VIREONIDAE

$$
\text { Cyclarhis guj }
$$

Cyclarhis gujanensis

Vireolanius leucotis

Vireo olivaceus

Hylophylus decurtatus

TURDIDAE

\section{Catharus ustulatus}

\section{Turdus maculirostris}

$$
\text { T. obsoletus }
$$

MIMIDAE
* Mimus longicaudatus
HIRUNDINIDAE
Progne chalybea
* Notiochelidon cyanoleuca
Stelgidopteryx ruficollis

$T$
$T$
$V$
$T$

$T$

T

$\mathrm{T}$

1

$\begin{array}{llll}4 & 5 & 3 & \mathrm{M}\end{array}$

T 45

$9 \mathrm{~F} P$

$\checkmark$

T $0 \mathrm{SF}$

$\begin{array}{llllllllll}\mathrm{T} & 3 & 5 & 4 & 5 & 2 & 1 & 20 & \mathrm{~F} & \mathrm{P}\end{array}$

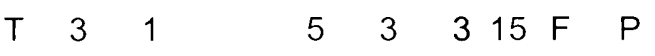

$T$

T

$11 \mathrm{SF}$

$0 \mathrm{SF}$

$0 \mathrm{SF}$

$0 \mathrm{SF}$

$0 \mathrm{SF}$

$\mathbf{T}$

$\mathrm{T}$

V

T

T

V

$2 \mathrm{SF}$

$0 \mathrm{D}$

$0 \mathrm{~F}$

$0 \mathrm{~F}$

$0 \mathrm{~F}$

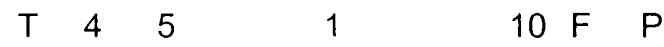

T 2 SF

$\begin{array}{llll}T & 1 & 3 & \end{array}$

T

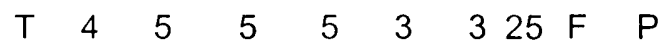

$\begin{array}{rrrrrrr}\mathbf{T} & 2 & 3 & 3 & 2 & 2 & 12 \mathrm{M} \\ \mathbf{T} & & 3 & & & 3 \mathbf{S F} \\ ? & & & & & 0 & \mathbf{0}\end{array}$

V

$T$

O SF

V

0 D

T 
APPENDIX. Continued.

ORDER

SITES $(\mathrm{m})$

FAMILY and Species

$\begin{array}{llllllllll}\text { R } & 50 & 100 & 150 & 220 & 280 & 350 & \text { N } & \text { H } & \text { P }\end{array}$

TROGLODYTIDAE

193

194

195

196

197

198

199

200

201

202

203

204

205

206

207

208

209

210

211

212

213

214

215

216

218

219

220

221
Campylorhynchus fasciatus

Thryothorus nigricapillus

T. mystacalis

T. sclateri

Troglodytes aedon

Microcerculus marginatus

POLIOPTILIDAE

Ramphocaenus melanurus

Polioptila plumbea

PARULIDAE

Parula pitiayumi
Dendroica petechia
Basileuterus fraseri
B. fulvicauda
THRAUPIDAE
Coereba flaveola
Chlorophanes spiza
Dacnis egregia
Hemithraupis guira
Euphonia laniirostris
E. saturata
Tangara cyanicollis
T. gyrola
Thraupis episcopus
Ramphocelus iceronotus
Piranga rubra
Tachyphonus luctuosus
CARDINALIDAE

CARDINALIDAE

Saltator maximus

S. atripennis

S. striatipectus

S. grossus

Cyanocompsa cyanoides
$\mathrm{T}$

$T$

$\begin{array}{llllllllll}\mathrm{T} & 3 & 3 & 3 & 3 & 2 & 3 & 17 & \mathrm{~F} & \mathrm{P}\end{array}$

T

$T$

T 22

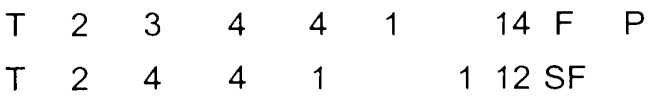

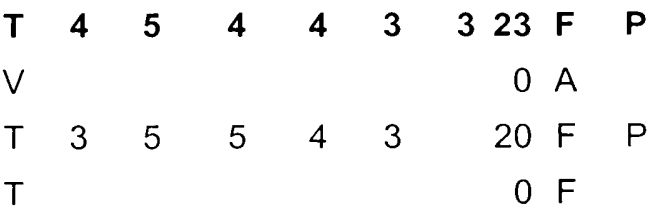

\begin{tabular}{|c|c|c|c|c|c|c|c|}
\hline $\mathrm{T}$ & & 1 & & 1 & & & $2 \mathrm{SF}$ \\
\hline V & & & & & & & $0 \mathrm{~F}$ \\
\hline V & & & & & & & $0 \mathrm{~F}$ \\
\hline $\mathrm{T}$ & 2 & 1 & & & 1 & & $4 \mathrm{SF}$ \\
\hline $\mathrm{T}$ & & & & & & & $0 \mathrm{~F}$ \\
\hline $\mathrm{T}$ & & & & & & & $0 \mathrm{~F}$ \\
\hline$T$ & & & & & & & $0 \mathrm{~F}$ \\
\hline V & & & & & & & $0 \mathrm{~F}$ \\
\hline $\mathrm{T}$ & & & 1 & 1 & & & $2 \mathrm{SF}$ \\
\hline V & & & & & & & $0 \mathrm{SF}$ \\
\hline$T$ & 1 & & & & & 1 & $2 M$ \\
\hline$T$ & 4 & 4 & 5 & 5 & 2 & 22 & $2 \mathrm{~F}$ \\
\hline $\mathrm{T}$ & & & 2 & & & & $2 \mathrm{SF}$ \\
\hline$?$ & & & & & & & $0 \mathrm{~F}$ \\
\hline $\mathrm{T}$ & & & & & & & $0 \mathrm{SF}$ \\
\hline $\mathrm{T}$ & 3 & 5 & 5 & 5 & 3 & 22 & $3 \mathrm{~F}$ \\
\hline $\mathrm{T}$ & 4 & 4 & 1 & 4 & 3 & $\begin{array}{ll}31 \\
1\end{array}$ & $9 \mathrm{~F}$ \\
\hline
\end{tabular}


APPENDIX. Continued.

\begin{tabular}{|c|c|c|c|c|c|c|c|c|c|c|}
\hline \multirow{2}{*}{\multicolumn{2}{|c|}{$\begin{array}{l}\text { ORDER } \\
\text { FAMILY and Species }\end{array}$}} & \multicolumn{8}{|c|}{ SITES (m) } & \multirow[b]{2}{*}{$\mathbf{P}$} \\
\hline & & $\mathbf{R}$ & 50 & 100 & 150 & 220 & 280 & 350 & $N$ & \\
\hline \multicolumn{2}{|r|}{ EMBERIZIDAE } & & & & & & & & & \\
\hline 222 & Rhodospingus cruentus & $\mathrm{T}$ & & & & & & & $0 \mathrm{SF}$ & \\
\hline 223 & Volatinia jacarina & $\mathrm{T}$ & & & & & & & $0 \mathrm{SF}$ & \\
\hline 224 & Oryzoborus angolensis & $\mathrm{T}$ & & & & & & & $0 \mathrm{SF}$ & \\
\hline 225 & Sporophila corvina & $\mathrm{T}$ & & & & & & & $0 \mathrm{SF}$ & \\
\hline 226 & S. nigricollis & $\mathrm{T}$ & & & & & & & $0 \mathrm{SF}$ & \\
\hline 227 & S. peruviana & $\mathrm{T}$ & & & & & & & $0 \mathrm{SF}$ & \\
\hline 228 & * S. telasco & V & & & & & & & $0 \mathrm{SF}$ & \\
\hline \multirow[t]{2}{*}{229} & Arremon aurantiirostris & $\mathbf{T}$ & 3 & & & & & & $4 F$ & $\mathbf{P}$ \\
\hline & ICTERIDAE & & & & & & & & & \\
\hline 230 & Cacicus cela & $\mathrm{T}$ & 1 & 3 & 2 & 2 & 2 & 2 & $10 \mathrm{SF}$ & \\
\hline 231 & C. microrhynchus & $T$ & 5 & 5 & 4 & 4 & 5 & 3 & $325 \mathrm{~F}$ & $\mathrm{P}$ \\
\hline 232 & Molothrus bonariensis & V & & & & & & & $0 \mathrm{D}$ & \\
\hline 233 & Molothrus oryzivorus & $\mathbf{T}$ & & & & & & & $0 D$ & \\
\hline 234 & Dives warszewiczi & $\mathrm{T}$ & & & & & & & 0 SF & \\
\hline 235 & Quiscalus mexicanus & V & & & & & & & $0 \mathrm{~A}$ & \\
\hline 236 & Icterus mesomelas & $\mathrm{T}$ & & & & & & & $0 \mathrm{SF}$ & \\
\hline \multirow[t]{2}{*}{237} & Sturnella bellicosa & $T$ & & & & & & & $0 \mathrm{D}$ & \\
\hline & PASSERIDAE & & & & & & & & & \\
\hline 238 & * Passer domesticus & V & & & & & & & $0 \mathrm{D}$ & \\
\hline
\end{tabular}

